\title{
POLICY OPTIONS FOR REDUCING DIETARY SODIUM INTAKE
}

\author{
Lindsay McLaren*† \\ for The School of Public Policy, University of Calgary
}

\section{SUMMARY}

Faced with soaring health-care costs, Canadian governments should consider creative ways to enable the population to stay healthy - and making it possible for Canadians to reduce their sodium intake is an extremely cost-effective way to do so. Excess sodium consumption is a risk factor for high blood pressure, stroke and heart disease. On average, Canadians consume $3,400 \mathrm{mg}$ of sodium a day (1,100 $\mathrm{mg}$ over recommended levels), at least three-quarters of which comes from processed foods. Any attempt at sodium reduction must therefore involve the food industry. This paper surveys sodium reduction efforts in jurisdictions around the globe, as well as past Canadian attempts, to provide provincial and federal policymakers with a comprehensive suite of lessons learned and a host of far-sighted policy recommendations ranging from food procurement to legislation and private sector engagement. Provincial governments, individually or together, must launch multi-pronged efforts involving food service companies, manufacturers, post-secondary institutes and the media to ensure that low-sodium alternatives are readily available, and that consumers are aware of them. They must also support federal action on changing dietary guidelines and introducing restrictions on food advertising to children. The benefits to be had are very real. In light of evidence showing that population-level intervention is superior to clinical intervention in terms of cost-effectiveness, returning up to $\$ 11.10$ for every dollar spent and generating tens of billions in direct health-care savings, there is a very strong case for investing in population-level sodium reduction interventions that will work. The time for governments to act is now.

\footnotetext{
* Correspondence to: Lindsay McLaren PhD, Department of Community Health Sciences, University of Calgary, 3280 Hospital Dr. NW, Calgary, Alberta, T2N 4Z6, Tel: (403) 210-9424, Email: Imclaren@ucalgary.ca

${ }^{\dagger}$ The author wishes to acknowledge the helpful comments of the anonymous referees.
} 


\section{OVERVIEW, OBJECTIVE, AND PARAMETERS OF THE PAPER}

There is an abundance of evidence that excess dietary sodium consumption constitutes a risk factor for high blood pressure, stroke, cardiovascular disease, and other adverse health outcomes. In Canada and elsewhere, the majority of the population consumes dietary sodium in excess of recommended maximum limits. Dietary sodium reduction lends itself to a populationlevel intervention strategy, wherein efforts are taken to decrease sodium intake across the population as a whole, including individuals with particularly high, as well as those with more moderate consumption of sodium. A population-level dietary sodium reduction strategy will by necessity involve the food industry, because most dietary sodium consumed by Canadians comes from sodium added to foods at processing.

The objective of this paper is to identify sodium reduction strategies that represent viable policy options for provincial governments in Canada. The paper is organized as follows. In Section 2, I provide an overview of sodium's functions and its implications for health, followed by a discussion of reasons why dietary sodium reduction lends itself to a population-level intervention approach in Section 3. In Section 4 I describe what is known about the population's sodium consumption in Canada and describe the pertinent administrative structure between levels of government, which affects the scope for policy options. Section 5 describes dietary sodium reduction efforts that have been undertaken in other jurisdictions, with a focus on identifying aspects that are informative to the Canadian context. In Section 6, I comment on existing surveillance capabilities in Canada as well as pertinent past and present intervention efforts. I conclude in Section 7 with discussion of an issue that is at the heart of population-level sodium reduction and on which its success arguably rests: whether it is possible to achieve meaningful and sustained population-level dietary sodium reduction using a voluntary approach to product reformulation. Policy recommendations for the federal and provincial governments are introduced throughout the paper.

As a final introductory note, it is important to acknowledge that excessive sodium intake is not the only diet-related threat to population health in Canada. For example, insufficient intake of fruits and vegetables has been identified as an important dietary concern for Canadians. ${ }^{I}$ A reasonable question, therefore, is why focus specifically on dietary sodium rather than a total diet approach to improving population health, such as that endorsed by the American Dietetic Association, ${ }^{2}$ where the focus is on accommodating all foods in moderation, rather than on specific foods or nutrients? There are several reasons why the sodium focus is justified; as outlined below, sodium is pervasive in our food supply, the sodium we consume comes from diverse (and sometimes surprising) food sources, and making changes to sodium alone in the food supply could have a significant impact on population health. Notably, however, the focus on sodium leads to certain policy recommendations (e.g., pertaining to nutrition labeling) that are consistent with a total diet approach; ${ }^{3}$ this paper's focus is not incompatible with a broader dietary approach to improving population health.

\footnotetext{
I Garriguet D. "Canadians' eating habits," Health Rep 2007, 18(2), May

Nitzke S, Freeland-Graves J, American Dietetic Association. "Position of the American Dietetic Association: Total diet approach to communicating food and nutrition information," J Am Diet Assoc 2007; 107:1224-1232. Note that the organization Dietitians of Canada does not appear to formally endorse a total diet approach (http://www.dietitians.ca/).

3 Op. cit.
} 


\section{SODIUM: FUNCTIONS AND IMPLICATIONS FOR HEALTH}

Sodium has many functions. As an essential element, sodium is required (in small amounts) for normal functioning of the body. ${ }^{4}$ Salt (the common name for sodium chloride) is widely used for preservation: its role as a food preservative dates back at least 5,000 years when the Chinese discovered that it could be used to store food over the winter, thus enabling community settlement. ${ }^{5}$ Salt is also used as a vehicle for the delivery of iodine to populations. Many countries, including Canada where it was made mandatory in 1949, use iodized salt as an inexpensive way to prevent iodine-deficiency disorders such as goiter, for which it has been highly successful. ${ }^{6}$

Currently, dietary sodium consumption in Canada and other developed countries is too high. For example, ${ }^{7}$ average daily sodium consumption among populations in France $(3,120 \mathrm{mg} /$ day $)$, Finland ( $3,300 \mathrm{mg} /$ day), Canada ( $3,400 \mathrm{mg} /$ day), the USA (3,435 mg/day), the UK $(3,460$ $\mathrm{mg} /$ day), Brazil (4,500 mg/day), and Turkey (7,200 mg/day) all exceed, ${ }^{8}$ some by a large margin, the $2,300 \mathrm{mg} /$ day Tolerable Upper Intake Level recommended by the US Institute of Medicine. ${ }^{9}$ Most sodium in these countries comes from processed foods. For example, a Danish study examined sources of sodium consumption among a sample of healthy adults using multiple 24-hour urine samples, a food diary, and a lithium marker technique that enables "household salt" (i.e., salt added at the table or while cooking) to be detected and quantified. ${ }^{10}$ They found that only approximately 10 percent of sodium could be attributed to "household salt" use, with the remainder (approximately 90 percent) coming from "non-household salt intake," meaning salt added during food processing or manufacturing, salt naturally occurring in foods, and salt eaten in restaurants. An earlier study ${ }^{11}$ estimated that approximately 11.6 percent of sodium is naturally occurring, leaving approximately $75-80$ percent of sodium coming from processed foods; this estimate is consistent with analyses of the Canadian food supply. ${ }^{12}$ Sodium's ubiquity reflects the many properties that make it highly desirable from a food processing standpoint: in addition to preservation and shelf life, salt and sodium-containing additives contribute to microbial food safety, protein binding, tenderness and mouth feel, control of fermentation in cheese and bread, maintenance of colour in meats, and flavour and texture. ${ }^{13}$

4 Sodium Working Group (SWG). Sodium reduction strategy for Canada-Recommendations of the Sodium Working Group, 2010. Report available online at: http://www.hc-sc.gc.ca/fn-an/nutrition/sodium/strateg/index-eng.php

5 He FJ, MacGregor GA. "A comprehensive review on salt and health and current experience of worldwide salt reduction programmes," J Hum Hypertens 2009; 23:363-384.

6 Canadian Public Health Association. Milestone: 1940s. Available online at

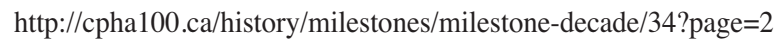

7 Sodium Working Group 2010 op. cit.

8 Because these estimates were based on different data collection methods, comparisons should be made with caution. See Sodium Working Group 2010 op. cit.

9 Institute of Medicine. Dietary Reference Intakes for Water, Potassium, Sodium, Chloride, and Sulfate. Washington (DC): National Academies Press; 2005.

10 Andersen L, Rasmussen LB, Larsen EH, Jakobsen J. "Intake of household salt in a Danish population," Eur J Clin Nutr 2009; 63:598-604.

11 Mattes RD, Donnelly D. "Relative contributions of dietary sodium sources," J Am Coll Nutr 1991; 10:383-393

12 Tanase CM, Griffin P, Koski KG. "Sodium and potassium in composite food samples from the Canadian Total Diet Study," J Food Composition Analysis 2011; 24: 237-243; Fischer PWF, Vigneault M, Huang R, Arvaniti K, Roach P. "Sodium food sources in the Canadian Diet," Appl Physiol Nutr Metab 2009; 34:884-892.

13 Sodium Working Group 2010 op. cit. 
Excess sodium intake has clear implications for health. There is particularly strong evidence for a direct relationship between sodium intake and blood pressure. ${ }^{14}$ This relationship has been demonstrated in laboratory-based animal studies, clinical intervention studies (i.e., treatment trials, which have shown that even a modest reduction in sodium intake among hypertensive patients can have an impact on blood pressure that is similar to single-drug treatment), observational epidemiological studies (e.g., higher blood pressure in communities living near salt water than in otherwise similar communities living near fresh water), and increasingly, in population-based intervention studies (described below). While most studies focus on adults, an association between sodium intake and blood pressure has also been observed in children, and some studies (mostly animal studies but at least one human study) indicate that high sodium intake during childhood is likely to predispose children to develop hypertension later in life. ${ }^{15}$ Hypertension is common (the lifetime risk is as high as 90 percent ${ }^{16}$ ); costly (globally, estimated direct and indirect costs in 2001 dollars of increased blood pressure totaled US\$370 billion and US $\$ 3,600$ billion respectively ${ }^{17}$ ); and it accounts for a significant burden of disease and death such that the World Health Organization considers increased blood pressure to be the leading preventable risk factor for death in the world. ${ }^{18}$

Aside from increased blood pressure and hypertension, there is evidence that excess dietary sodium intake is a risk factor for stroke (direct, as well as indirect through blood pressure), cardiovascular disease, and other health outcomes including left ventricular hypertrophy, stomach cancer, and renal disease. ${ }^{19}$ The nature of available evidence, especially for cardiovascular disease, permits the assertion that sodium reduction can reduce the incidence of new cases, both among the population at large and among hypertensive individuals. This evidence has also informed recommendations of sodium reduction in particular patient groups (e.g., those with kidney disease, and diabetics) as a way of staving off deterioration of the condition. ${ }^{20}$

${ }^{14} \mathrm{He}$, MacGregor 2009 op. cit.

15 He FJ, MacGregor GA. "Importance of salt in determining blood pressure in children: meta-analysis of controlled trials," Hypertens 2006; 48:861-869.

16 Vasan RS, Beiser A, Seshadri S, Larson MG, Kannel WB, D’ Agostino RB, Levy D. "Residual lifetime risk for developing hypertension in middle-aged women and men: The Framingham Heart Study,” JAMA 2002; 287:10031010.

17 Gaziano TA, Bitton A, Anand S, Weinstein MC, International Society of Hypertension. "The global cost of nonoptimal blood pressure," J Hypertens 2009; 27:1472-1477.

18 Ezzati M, Lopez AD, Rodgers A, Vander Hoorn S, Murray CJ. "Comparative risk assessment collaborating group," Lancet 2002;360(9343):1347-60; Lopez AD, Mathers CD, Ezzati M, Jamison DT, Murray CJL. "Global and regional burden of disease and risk factors, 2001: systematic analysis of population health data," Lancet 2006; 367 (9524):1747-1757.

19 Mohan S, Campbell NRC. "Salt and high blood pressure," Clin Sci 2009; 117:1-11; Strazzullo P, D’Elia L, Kandala N-B, Cappuccio FP. "Salt intake, stroke, and cardiovascular disease: meta-analysis of prospective studies," BMJ 2009; 339:b4567; He \& MacGregor 2009 op. cit.; MacGregor GA, Sever PS. "Salt - overwhelming evidence but still no action: can a consensus be reached with the food industry?" BMJ 1996; 312:1287-1289.

${ }^{20} \mathrm{He}$, MacGregor 2009 op. cit. 
Against the backdrop of this sizeable literature documenting the health risks associated with excess dietary sodium consumption, it is important to acknowledge a recent flurry of attention over studies whose findings appear to contradict this literature. For example, the conclusions of two recent studies dispute the benefits of dietary sodium reduction.$^{21}$ However, these studies have been subject to significant methodological critique..$^{22}$ Accordingly, though continued research on sodium's health risk in different populations is important, the literature overall strongly supports the position that excess sodium consumption presents important risks to cardiovascular health.

\section{DIETARY SODIUM REDUCTION: THE POPULATION-LEVEL INTERVENTION APPROACH}

The reduction of dietary sodium intake lends itself to a population-level intervention approach. A population-level intervention may be defined as an intervention (program or policy), operating within or outside the health sector, that targets a whole population (jurisdiction, institution, etc.) without regard to variation in individual risk status, and that has the potential to impact health at the population level. ${ }^{23}$ The reduction of dietary sodium intake lends itself to a population-level intervention approach for several reasons. First, in many countries, a majority consumes excess sodium, and thus sodium reduction is broadly pertinent across the population. Second, the association between sodium intake and blood pressure is linear with no obvious threshold, ${ }^{24}$ and thus there is no clear cutoff with which to identify a discrete high-risk group of individuals for targeted intervention.

21 Taylor RS, Ashton KE, Moxham T, Hooper L, Ebrahim S. "Reduced dietary salt for the prevention of cardiovascular disease: a meta-analysis of randomized controlled trials," (Cochrane review). Am J Hypertens 2011; 24:843-853; Stolarz-Skrzypek K, Kuznetsova T, Lutgarde T, Tikhonoff V, Seidlerova J, Richart T. et al. "Fatal and nonfatal outcomes, incidence of hypertension, and blood pressure changes in relation to urinary sodium excretion," JAMA 2011; 305:1777-1785.

22 Letters to the editor following the publication of Stolarz-Skrzypek's study highlight methodological flaws including threats to both internal and external validity (see Aleksandrova K, Pischon T, Weikert C. "Letter: Urinary sodium excretion and cardiovascular disease mortality," JAMA 2011; 306:1083 and six other letters in the same issue). As for the Taylor et al. study, experts emphasized that the null findings reflect insufficient numbers of randomized controlled trials (the study design to which the review was restricted); further, concern about potential conflict of interest has been expressed: the editor of the American Journal of Hypertension, which published the study, has been a consultant for the Salt Institute, an industry advocacy group (see CBC radio. "Salt: interview with Dr. Norm Campbell, Professor of Medicine at the University of Calgary," The Homestretch (Alberta programming), July 11, 2011. Available online at: http://www.cbc.ca/video/\#/Radio/Local_Shows/Alberta/The_Homestretch/1366093611/ID=2052384638).

23 Rose G. The strategy of preventive medicine. Oxford: Oxford University Press, 1992. [Reprinted. Rose's strategy of preventive medicine. Oxford: Oxford University Press, 2008]; McLaren L, McIntyre L, Kirkpatrick S. "Rose's population strategy of prevention need not increase social inequalities in health," Int J Epidemiol 2010; 39:372-377; CIHR Institute of Population and Public Health. Available online at: http://cihr-irsc.gc.ca/e/13777.html

24 Sodium Working Group 2010 op. cit. 
Third, in line with the WHO's designation of elevated blood pressure (directly linked to sodium intake) as the leading preventable risk factor for death in the world, several modeling studies have illustrated that the population-level impact of a widespread reduction in sodium intake is potentially very large. ${ }^{25}$ For example, Joffres et al. estimated that a population-level sodium reduction of $1,840 \mathrm{mg} /$ day among Canadians (which would bring Canada in line with the Institute of Medicine recommendations) would lead to a 30 percent reduction in hypertension prevalence. ${ }^{26}$ The potentially significant impact of population sodium reduction is related to population intervention theory. ${ }^{27}$ As illustrated in Figure 1, population-level intervention theoretically has significant leverage to impact the prevalence of health outcomes in a sustainable manner, by shifting a population's risk distribution in a direction of reduced risk. This leverage stems, in part, from what Rose termed the sociological argument for population-level prevention: a population is a coherent social entity, and risk distributions (e.g., the frequency distribution for dietary sodium intake across a population) tend to shift as a whole. ${ }^{28}$

FIGURE 1. DEPICTION OF THE HYPOTHETICAL IMPACT OF A POPULATION-LEVEL INTERVENTION, ACHIEVED BY SHIFING THE FREQUENCY DISTRIBUTION OF THE RISK FACTOR IN A DIRECTION OF LOWER RISK (ADAPTED FROM ROSE 1992)

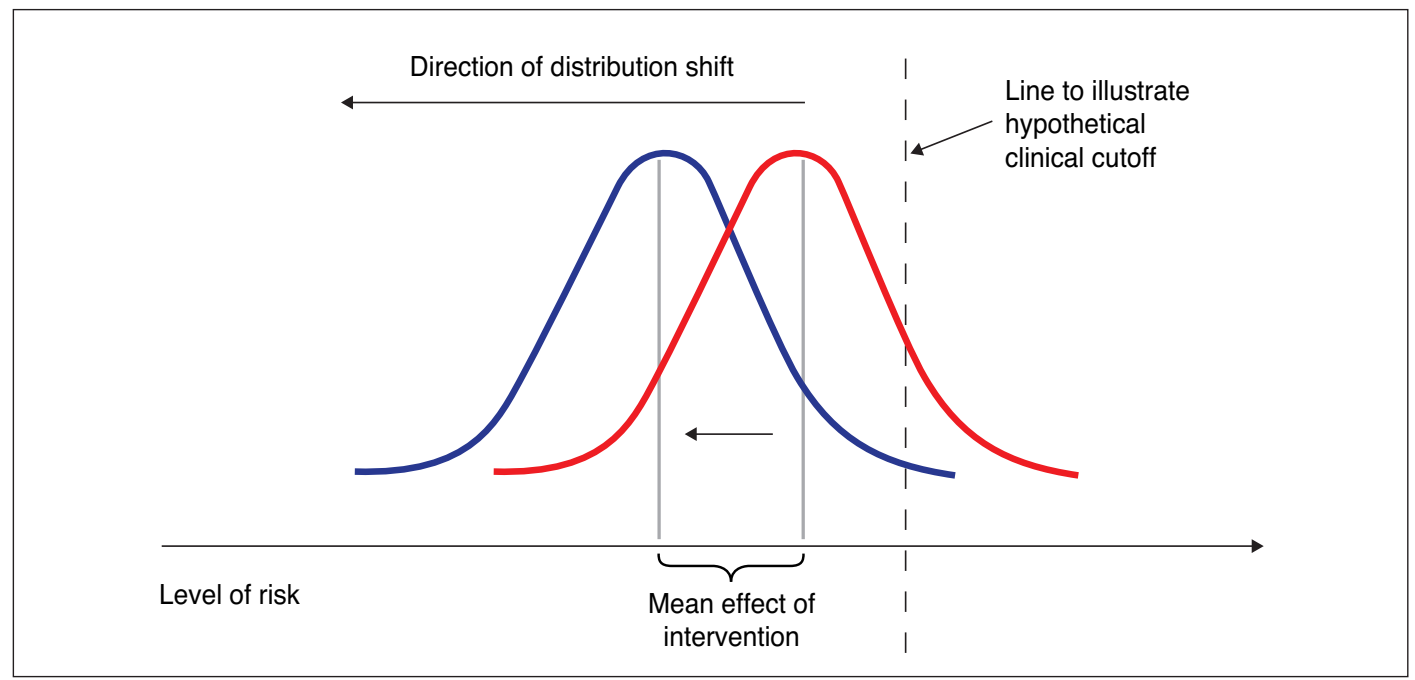

Fourth, and related to the potentially very large health impact of population intervention, successful population-level sodium reduction could yield significant cost savings. Several studies have estimated the potential cost savings associated with achieving particular sodium reduction targets, regardless of the mechanism(s) used (or their cost). ${ }^{29}$ For example,

25 Joffres MR, Campbell NRC, Manns B, Tu K. "Estimate of the benefits of a population-based reduction in dietary sodium additives on hypertension and its related health care costs in Canada," Can J Cardiol 2007; 23:437-443; Smith-Spangler CM, Juusola JL, Enns EA, Owens DK, Garber AM. "Population strategies to decrease sodium intake and the burden of cardiovascular disease: a cost-effectiveness analysis," Ann Intern Med 2010; 152:481-487.

26 Joffres et al. 2007 op. cit.

27 Rose 1992 op. cit.

${ }^{28}$ Op. cit.

29 Joffres et al. 2007 op. cit; Dall TM, Fulgoni VL, Zhang Y, Reimers KJ, Packard PT, Astwood JD. "Potential health benefits and medical cost savings from calorie, sodium, and saturated fat reductions in the American diet," Am J Health Promotion 2009; 23:412-422. 
Joffres et al. estimated that the 30 percent reduction in hypertension prevalence noted above that could be achieved by a population-level sodium reduction of $1,840 \mathrm{mg} /$ day in Canada would lead to savings of approximately $\$ 430$ million per year in direct health-care costs associated with hypertension alone (i.e., physician visits, laboratory tests, and medication use).$^{30}$ Other studies have estimated the cost effectiveness of particular interventions, which entails estimating and taking into account the costs of the intervention as well as potential cost savings. ${ }^{31}$ These studies consistently indicate that population-level sodium reduction interventions are cost-effective, with costs saved exceeding, often by a large margin, the costs of the intervention. For example, Smith-Spangler et al. estimated the potential health benefits and costs associated with two governmental strategies to reduce dietary sodium in the US: i) collaboration with industry to set voluntary maximum sodium targets for processed foods, modeled on the UK experience (which is described below); and ii) a tax on sodium used in food production. ${ }^{32}$ Based on their models, collaboration with industry to achieve a 9.5 percent reduction in the population's sodium intake (which was achieved in the UK) would yield approximately $\$ 32.1$ billion in savings in direct medical costs over the lifetime of adults currently aged 45-85 years; the corresponding number for the tax intervention was \$22.4 billion. In Canada, these potential savings would be enjoyed almost wholly by provincial governments, which have constitutional responsibility for health care. It is in the interests of provincial governments, therefore, to initiate action on sodium reduction, and to pressure the federal government for action that occurs federally.

Of particular interest are studies that estimate the cost-effectiveness of population-level interventions and compare it to that of clinical interventions (i.e., drug treatment for individuals at elevated risk). Bibbins-Domingo et al. conducted such a comparison and found the population-level approach to be superior to the clinical approach in terms of costeffectiveness. ${ }^{33}$ Specifically, a population-level intervention to achieve a $3 \mathrm{~g} /$ day salt reduction $(1,179 \mathrm{mg} /$ day sodium reduction) was estimated to cost $\$ 300$ million annually, leading to annual health-care savings in the range of $\$ 12.1$ billion to $\$ 20.4$ billion, and annual QALY (quality-adjusted life-year) gains in the range of 220,000 to 350,000; leading to an overall estimated range of $\$ 7.30$ to $\$ 11.10$ saved per $\$ 1$ spent on the intervention (the range of estimates reflects a plausible range of impact). By contrast, providing anti-hypertensive drugs to all persons with hypertension was estimated to cost $\$ 19.5$ billion annually, leading to annual health-care savings of $\$ 14.2$ billion, and annual QALY gains of 360,000; leading to an estimated $\$ 0.40$ saved per $\$ 1$ spent on the intervention. Even a population-level intervention that achieved a more modest $1 \mathrm{~g} /$ day salt reduction $(393 \mathrm{mg} /$ day sodium reduction) over a 10 -year period would outperform the clinical intervention in terms of cost savings - an estimated range of $\$ 1.60$ to $\$ 2.30$ saved per $\$ 1$ spent on the intervention versus $\$ 0.40$. The strategy of providing anti-hypertensive medication to all persons with hypertension could be cost-effective, according to the authors, if it were added to a successful population-level sodium reduction intervention. On these cost-effectiveness studies, it is important to note that they may actually underestimate the cost-effectiveness of population-level interventions, to the

\footnotetext{
30 Joffres et al. 2007 op. cit.

31 Wang G, Labarthe D. "The cost effectiveness of interventions designed to reduce sodium intake," J Hypertens 2011; 29:1693-1699.

32 Smith-Spangler et al. 2010 op. cit.

33 Bibbins-Domingo K, Chertow GM, Coxson PG, Moran A, Lightwood JM, Pletcher MJ, Goldman L. "Projected effect of dietary salt reductions on future cardiovascular disease," New Engl J Med 2010; 362:590-599.
} 
extent that they do not fully take into account a) the savings that would accrue from having fewer hypertensives needing drugs because of the population-level sodium reduction, and b) the potentially declining cost over time of administering a population-level intervention. A regulatory intervention could have significant initial costs but much smaller subsequent costs once the infrastructure is in place.

Fifth, the observation that processed foods constitute the major source of sodium for the population ${ }^{34}$ means that there is an obvious leverage point for population-level intervention. It is widely acknowledged that successful dietary sodium reduction in populations will hinge on the cooperation of the food industry. ${ }^{35}$ In jurisdictions worldwide with active dietary sodium reduction strategies, processed foods constitute a key focus, and efforts include product reformulation (i.e., reducing sodium content in existing products) as well as strategies to enable consumers to make healthy selections through effective labeling for example. ${ }^{36}$ Key contributors to dietary sodium include foods that are high in sodium but eaten in moderation (e.g., processed meats) as well as foods that are moderate in sodium but eaten in larger quantities (e.g., bread). ${ }^{37}$ That some of our sodium consumption comes from foods not typically thought of as salty suggests that some sodium reduction could occur without consumers even noticing a change in taste or texture; indeed, at least one study demonstrated that consumers could not detect a reduction in sodium in breads when introduced gradually. ${ }^{38}$ The possibility that some sodium could be removed from our diet unnoticeably helps alleviate concern about offsetting behaviour - i.e., the possibility that individuals will respond to reduced sodium in foods by adding more salt at the table.

Finally, several of the population-level intervention strategies that are pertinent to sodium reduction (e.g., mass media campaigns, food product labeling, food product reformulation) have also been used or discussed in the context of other diet-related health issues. For example, mass media campaigns and nutrition labeling have been used to assist consumers in identifying foods that are lower in saturated fats and added sugar, and in calories, ${ }^{39}$ and product reformulation has been used to ensure exposure to important nutrients such as folate fortification via grain products. ${ }^{40}$ Due to shared strategies, population-level sodium reduction is complementary to other population-level health priorities, and efforts could theoretically be integrated into existing nutrition policy and infrastructure.

34 Although I do not focus on developing countries in this paper, it is important to acknowledge that in several developing countries, most sodium comes from salt added by the individual when preparing food or eating, and thus sodium reduction interventions in those countries would be justified in taking a different tack, with a larger focus on individual behavior change.

35 Sodium Working Group 2010 op. cit.

36 Webster JL, Dunford EK, Hawkes C, Neal BC. "Salt reduction initiatives around the world," J Hypertens 2011; 29:1043-1050.

37 Garriguet D. "Sodium consumption at all ages," Health Rep 2007;18:47-52; Fischer et al. 2009 op. cit.

38 Girgis S, Neal B, Prescott J, Prendergast J, Dumbrell S, Turner C, Woodward M. "A one-quarter reduction in the salt content of bread can be made without detection," Eur J Clin Nutr 2003; 57:616-620.

39 Health Canada. Nutrition Labeling — Food and Nutrition. Available online at http://www.hc-sc.gc.ca/fn-an/labeletiquet/nutrition/index-eng.php

40 Riciutto LE, Tarasuk V. “An examination of income-related disparities in the nutritional quality of food selections among Canadian households from 1986-2001," Soc Sci Med 2007; 64:186-198; Health Canada. Vitamins and Minerals - Nutrition and Healthy Eating. Available online at www.healthcanada.gc.ca/fortification 


\section{THE CANADIAN CONTEXT}

\section{a) Administrative structure}

In Canada, health (including public health, with which population-level sodium reduction is most closely aligned) involves both federal and provincial/territorial levels of government. ${ }^{4 I}$ However, when identifying viable policy options to reduce dietary sodium consumption, it is necessary to clarify the jurisdiction of pertinent intervention options. Importantly, a significant proportion of food and nutrition policy falls within federal jurisdiction. Health Canada is responsible for "establishing policies, setting standards and providing advice and information on the safety and nutritional value of food; promoting the nutritional health and well-being of Canadians by collaboratively defining, promoting and implementing evidence-based nutrition policies and standards; and administering the provisions of the Food and Drugs Act that relate to public health, safety and nutrition." ${ }^{42}$ Thus, intervention strategies such as food product reformulation, food product labeling, and development of dietary guidelines occur at the national level, which leaves provincial governments with a supporting or advocacy role.

Key message: Due to the administrative structure of health (including public health) in Canada, many intervention strategies to achieve dietary sodium reduction must occur at the national level, thus leaving provincial governments an important supporting or advocacy role.

One might wonder whether there is any exception to this. In the 2001 Alberta health policy report, A Framework for Reform: Report of the Premier's Advisory Committee on Health (aka the Mazankowski Report), ${ }^{43}$ a number of recommendations for provincial health reform were identified, one of which was "taking the lead in updating Canada's food guide." In 2002, the Alberta government announced that it would adopt this recommendation, and in 2003 a report from a team tasked with implementing the recommendations stated that Alberta had "communicated to Health Canada its support to review the current Canada's Food Guide ..."(http://www.health.alberta.ca/documents/Health-Reform-Team-Report-2003.pdf). The Food Guide was indeed updated. ${ }^{44}$ However it does not appear that Alberta played any special role in this process. Nonetheless, this example suggests that there may be an opportunity for provincial leadership on national issues related to food and nutrition.

Notwithstanding the predominantly federal nature of food policy in Canada, there is opportunity for dietary sodium reduction strategies to be adopted at the provincial level via food service environments that fall under provincial jurisdiction, including schools, child-care settings, recreation settings, hospitals, and long-term care facilities. Provincial governments could support the development and implementation of food procurement policies that set limits on the amount of sodium permitted in foods served or sold within such settings.

\footnotetext{
${ }^{41}$ Health Canada. About Health Canada. Available online at http://www.hc-sc.gc.ca/ahc-asc/index-eng.php; Wilson K. "The complexities of multi-level governance in public health," Can J Public Health 2004; 95:409-412.

${ }^{42}$ Health Canada. Food and Nutrition - Main Page. Available online at http://www.hc-sc.gc.ca/fn-an/index-eng.php

43 Government of Alberta. A Framework for Reform: Report of the Premier's Advisory Committee on Health. 2001. Available online at http://www.health.alberta.ca/documents/Mazankowski-Report-2001.pdf

44 Health Canada. The Revision Process - Canada's Food Guide. Available online at http://www.hc-sc.gc.ca/fnan/food-guide-aliment/context/rev_proc-eng.php
} 
Key message: Although much of food and nutrition policy falls within the federal jurisdiction in Canada, there is nonetheless opportunity for individual provinces to achieve dietary sodium reduction via food procurement environments that fall under provincial jurisdiction (e.g., schools, child care settings, hospitals).

In addition to involving both federal and provincial levels of government, it is important to note that public health, in recognition of the broad and multi-jurisdictional nature of health determinants, further engages with various provincial government ministries (e.g., education, agriculture, human services, recreation, and health) and various non-governmental organizations (e.g., health professional organizations and health charities; the private sector including food service vendors). The range of stakeholders potentially involved in populationlevel sodium reduction points to one policy recommendation:

Policy recommendation: Because of the inherently cross-ministerial and crosssectoral nature of population-level sodium reduction, sodium reduction efforts must, from the outset, engage representatives from relevant government ministries and relevant non-governmental organizations (both civil society and business).

\section{b) Dietary sodium intake in Canada}

Excess dietary sodium is currently a public health concern in Canada. The estimated average sodium intake, not including sodium added at the table or during cooking, is 3,092 mg/day, based on data from the 2004 Canadian Community Health Survey (CCHS).$^{45}$ Based on CCHS estimates, among individuals age nine to 70 years, over 85 percent of men and 63-83 percent of women had sodium intake exceeding the Institute of Medicine's recommended Tolerable Upper Intake Level (UL) of 2,300 mg/day of sodium. Excess sodium intake was also common among children, with the percent exceeding the UL ranging from 77 percent in respondents age one to three years, to 97 percent in teenage boys (age 14 to 18 years). ${ }^{46}$ Because the CCHS estimates did not include salt added at the table or during cooking, they were adjusted upward to arrive at the overall estimate of $3,400 \mathrm{mg} /$ day of sodium for Canadians. ${ }^{47}$ Provinces that differed significantly from the Canadian average in the CCHS were Quebec and British Columbia (higher than the Canadian average) and Ontario (lower than the Canadian average). ${ }^{48}$

The sodium that we (Canadians) consume comes from various food products. Garriguet identified, on the basis of the 2004 CCHS, the following ten food/beverage groupings as the main contributors to sodium, accounting for over half of all sodium consumed by Canadians: pizza, sandwiches, submarines, hamburgers, and hotdogs (19.1 percent); soups (7.4 percent); pasta (5.7 percent); liquid milk and milk-based beverages (4.0 percent); poultry and poultry dishes ( 3.8 percent); potatoes ( 3.4 percent); cheese ( 3.2 percent); cereals ( 3.0 percent); beef (3.0 percent) and sauces (2.9 percent).$^{49}$ Using a more nuanced approach, Fischer et al.

\footnotetext{
45 Garriguet 2007 op. cit.

46 Op. cit.

47 Sodium Working Group 2010 op. cit.

48 Garriguet 2007 op. cit.

49 Op. cit.
} 
identified the following top ten contributors to Canadians' sodium consumption: breads (13.9 percent), processed meats ( 8.9 percent), pasta dishes (5.7 percent), cheese (5.4 percent), vegetables (other) (5.1 percent), milk products (4.4 percent), red meat dishes (4.2 percent), poultry (other) (3.9 percent), gravies and sauces ( 3.8 percent), and soups (other) (3.6 percent). ${ }^{50}$ Note that in the previous list, "other" means "other than canned, pickled, smoked, or dried" i.e., excluding the versions that tend to be higher in sodium. Thus, our sodium comes not only from foods that are high in sodium (and taste salty) and that we consume in moderation, but also from foods that are moderate in sodium but that we consume in higher quantities, such as bread and milk.

In addition to excess sodium consumption overall, a key population health concern is socioeconomic inequalities in consumption. Socioeconomic inequalities in overall diet have been observed in Canada. An analysis of the CCHS 2.2 data showed that higher income adequacy and/or higher household education was associated with a better nutrition profile, characterized by greater intake of milk and alternatives, fruit and vegetables, vitamins, minerals, and fiber. ${ }^{51}$ Processed foods (e.g., foods with added sugars and fats) are less expensive, on a cost-per-calorie basis, than less processed foods (e.g., fresh fruits and vegetables), ${ }^{52}$ which likely contributes to poorer diet (perhaps including more sodium) among those with limited financial resources. Although it is plausible that sodium intake may vary by socioeconomic status, current available evidence does not support a strong conclusion on this issue..$^{53}$ Nonetheless, from a population health perspective it is important to ensure that population-level sodium reduction interventions do not inadvertently lead to a widening in dietary inequalities.

\section{DIETARY SODIUM REDUCTION IN OTHER JURISDICTIONS}

To help inform viable policy options for sodium reduction, I reviewed dietary sodium reduction initiatives in other jurisdictions worldwide. Recognizing that differences in institutions and governance structure between countries limits the extent to which intervention efforts and findings are transferable to Canada, I focused on initiatives in jurisdictions that have at least some comparability to our context (e.g., the U.K.) or that are otherwise

50 Fischer et al. 2009 op. cit.

51 Tarasuk V, Fitzpatrick S, Ward H. "Nutrition inequities in Canada," Appl Physiol Nutr Metab 2010; 35:172-179.

52 Drewnowski A. "Obesity, diets, and social inequalities," Nutr Rev 2009; 67(Suppl 1):S36-39.

53 Two Canadian studies reported positive associations between socioeconomic factors and sodium purchase (see Ricciuto \& Tarasuk 2007 op. cit.) and consumption -i.e., higher sodium among those of higher socioeconomic circumstances - (see Dubois L, Girard M. "Social position and nutrition: a gradient relationship in Canada and the USA," Eur J Clin Nutr 2001; 55:366-373). However, the association was reduced to non-significance when adjusting for energy differences in the Ricciuto and Tarasuk study, suggesting that higher sodium among higher income people reflects that they purchase more food. In the Dubois and Girard study, the association varied by sex and by outcome, with men of lower socioeconomic circumstances more likely to consume too much sodium than men of higher socioeconomic circumstances. Ransome (Assessment of dietary intake in accordance with recommendations to reduce the risk of cancer among adult Alberta residents. M.Sc. thesis, Department of Agricultural, Food, and Nutritional Science, University of Alberta, 2001) reported that among men in the Alberta Nutrition Survey, a lower income was associated with lower sodium consumption than a higher income; no associations with education were observed. The mixed nature of the findings may reflect that the healthier diet observed among those of higher income and / or education (see Tarasuk et al. 2010 op. cit.) included greater intake of certain products/nutrients (such as milk and alternatives) that are healthy but also key contributors to sodium intake in the population due to the quantity of intake. (See Garriguet 2007 op. cit; Fischer et. al. 2009 op. cit.) 
informative (e.g., Finland differs in many ways from Canada, but their focus on contained food procurement environments is informative for provincial governments and in fact is consistent with efforts already underway in, for example, Alberta [see below]). I begin by describing international efforts, followed by a description of initiatives underway in specific jurisdictions.

\section{a) The international context}

The World Health Organization (WHO) has identified excess dietary sodium intake as a global problem, and is working to facilitate sodium reduction in countries worldwide. In 2003 the WHO, in conjunction with the United Nations Food and Agricultural Organization, set a worldwide target of less than $5 \mathrm{~g}$ per day of salt per person, which equates to $1,965 \mathrm{mg}$ of sodium per day. ${ }^{54}$ This recommendation (which was accompanied by recommendations for intake of other nutrients) was based on an extensive review of literature by an expert panel of scientists. ${ }^{55}$ The endorsement of the global $<5 \mathrm{~g} /$ day target $(<1,965 \mathrm{mg}$ /day of sodium) was followed by a series of meetings focused on specific aspects of this worldwide goal:

- In 2006, a meeting in Paris focused on reducing salt intake in populations. ${ }^{56}$

- In 2007, an expert panel in Luxembourg focused on salt as a vehicle for fortification. ${ }^{57}$

- In July 2010, a meeting in London focused on creating an enabling environment for population-based salt reduction strategies, in conjunction with the UK Food Standards Agency. ${ }^{58}$

- In October 2010, a meeting in Calgary focused on sodium in conjunction with the government of Canada. ${ }^{59}$

The 2006 meeting resulted in the development of a three-pillar strategy that the WHO recommends for countries that are pursuing national sodium reduction. ${ }^{60}$ The three pillars are:

- Product reformulation;

- Consumer awareness and educational campaigns; and

- Environmental changes (e.g., nutrition labeling)

\footnotetext{
54 World Health Organization (WHO). Diet, nutrition and the prevention of chronic diseases: Report of a joint WHO/FAO expert consultation. Geneva: WHO; 2003.

55 He, MacGregor 2009 op. cit.

56 World Health Organization (WHO 2007) Reducing salt intake in populations: Report of a WHO forum and technical meeting, Paris 2006.p 3. www.who.int/dietphysicalactivity/Salt_Report_VC_april07.pdf.

57 World Health Organization (WHO 2008). Salt as a vehicle for fortification. Report of a WHO Expert Consultation, Luxembourg, 2122 March 2007. http://whqlibdoc.who.int/publications/2008/9789241596787_eng.pdf.

58 World Health Organization (WHO 2010a). Creating an enabling environment for population-based salt reduction strategies: Report of a joint technical meeting held by WHO and the Food Standards Agency, United Kingdom, July 2010. Geneva: WHO Press, 2010.

59 World Health Organization (WHO 2010b). Sodium: Surveillance, Monitoring, and Evaluation. Strategies to monitor and evaluate population sodium consumption and sources of dietary sodium, and relevant knowledge, attitudes and behaviours. Proceedings of a technical meeting jointly convened by WHO and the Government of Canada. Calgary, October 2010.

60 World Health Organization 2007 op. cit.; Penney S. Dropping the Salt: practical steps countries are taking to prevent chronic non-communicable diseases through population-wide dietary salt reduction. Prepared for the Public Health Agency of Canada, 2009.
} 
The WHO framework includes recommended steps aligned with each pillar. ${ }^{61}$ For example, product reformulation involves identifying the foods that are the main contributors to population-level salt intake; raising awareness within government and among food producers of high salt content within foods; targeting major food producers or trade organizations to standardize the salt content of foods via voluntary or regulatory mechanisms; and assisting small businesses to work towards salt-reduction targets. Consumer awareness and education involves identifying a simple, clear, and coherent message about salt; developing a communication strategy/ies including appropriate avenues of communication; identifying key groups and individuals responsible for increasing awareness; and identifying target population groups. Environmental change involves setting a sodium reduction target; developing clear, simple, culturally acceptable and easily understandable nutrition labels; and developing specific standards for provision of nutrition information for restaurant and other meal providers. All of these steps are viable (i.e., can or have been implemented, either for sodium or other nutrients) in Canada.

Another international initiative is the European Union (EU) framework, which was developed in 2008. The aim of the EU framework is to support EU countries working towards achieving the WHO target of $<5 \mathrm{~g} /$ day of salt intake $(<1,965 \mathrm{mg} /$ day of sodium), and is characterized by: development of a nutrition labeling scheme (underway) that is consistent across EU countries; identification of a shortlist of 12 food categories that represent the largest potential opportunity for impact, from which countries must select at least five on which to focus; and a recognition of the need to reduce sodium in foods at all price levels so that sodium reduction benefits everyone. ${ }^{62}$ Participation in the EU framework by member states is voluntary.

In the next section I describe sodium reduction interventions that have been undertaken in jurisdictions worldwide. Prior to identifying interventions and assessing their implementation viability in Canada, however, I highlight the need to have in place surveillance capacity to enable monitoring of trends over time and progress towards a target.

Policy recommendation: The federal government, with the support of provincial governments, should fund a system for population-based dietary monitoring. Data should be gathered at regular intervals, and methods (i.e., sampling, data collection techniques) should stay as consistent as possible from cycle to cycle. The monitoring system should be designed to enable monitoring of trends across the population as a whole, as well as for subgroups defined based on age, sex, and socioeconomic circumstances.

Policy recommendation: The federal government, with the support of provincial governments, should formally endorse a target for average population sodium intake and a proposed time frame for its achievement. The suggested target is the Canadian Sodium Working Group's (SWG) target of $<2,300 \mathrm{mg} /$ day of sodium, which is based on the Institute of Medicine's recommendation.

\footnotetext{
61 Penney 2009 op. cit.

62 Sodium Working Group 2010 op. cit.
} 


\section{b) Sodium reduction strategies in other jurisdictions}

Prompted by local data indicating excess sodium consumption, many countries worldwide have developed national sodium reduction strategies. Although some countries have a lengthy history of sodium reduction activity (e.g., Finland, where efforts have been ongoing since the 1970s), most initiatives are more recent, and the number of countries with active programs has increased enormously since the early 2000 s when the WHO first publicized the $<5 \mathrm{~g}$ salt/day $\left(1,965 \mathrm{mg}\right.$ sodium/day) global target. ${ }^{63}$

Several comprehensive reviews of existing sodium reduction programs have been published, to which the reader is directed for more detail. ${ }^{64}$ Below, I summarize highlights of sodium reduction efforts in jurisdictions with active programs, focusing on initiatives for which data on impact are available and/or those with attributes that make them otherwise informative for the Canadian context. There is a fair amount of similarity across programs, with most programs including education/awareness campaigns (to inform the public and/or health professionals), collaboration with the food industry towards product reformulation and helpful nutrition labeling, and development of a mechanism for monitoring progress towards a stated intake goal. I discuss at some length efforts in Finland (because it has the longest-running sodium reduction program, and the greatest demonstrated impact) and in the UK (because the country and the program have similarities with Canada, and the UK approach was in fact used as a model in the development of the strategy developed by Canada's Sodium Working Group), with briefer descriptions of initiatives in other jurisdictions. I also consider recent initiatives in US jurisdictions (counties) that, despite lack of impact data so far (it is too early) may be particularly informative for provincial governments.

\section{FINLAND}

In Finland, national sodium reduction efforts began in 1978. Since then, population-wide salt consumption has decreased from $12 \mathrm{~g}$ /day to less than $9 \mathrm{~g}$ /day (sodium reduction from $5,000 \mathrm{mg} /$ day to $3,300 \mathrm{mg} /$ day), coronary heart disease and stroke mortality have decreased by over 75 percent, and life expectancy has increased by over five years. ${ }^{65}$ Other risk factors worsened during this time period (e.g., body mass index and alcohol consumption increased), suggesting that health improvements reflect sodium reduction. ${ }^{66}$ With some small exceptions, the decrease in sodium was similar in different geographic areas, in men and women, and across education groups, thus representing a truly population-wide effect. ${ }^{67}$

\footnotetext{
${ }^{63}$ World Health Organization 2010 op. cit.; Penney S. Dropping the Salt 2: A database of global activities and plans to prevent chronic non-communicable diseases through population-wide dietary salt reduction. Prepared for the Public Health Agency of Canada, 2011.

${ }^{64}$ See Penny 2009 op. cit.; Penney 2011 op. cit. Webster et al. 2011 op. cit.; Mohan S, Campbell NRC, Willis K. "Effective population-wide public health interventions to promote sodium reduction." CMAJ 2009; 181: 605-609; He, MacGregor 2009 op. cit.

65 He, MacGregor 2009 op. cit.; Webster et al. 2011 op. cit.

66 Laatikainen T, Pietinen P, Valsta L, Sundvall J, Reinivuo H, Tuomilehto J. "Sodium in the Finnish diet: 20 year trends in urinary sodium excretion among the adult population," Eur J Clin Nutr 2006; 60:965-70.

67 Op. cit.
} 
Highlights of Finland's national sodium reduction strategy, for which leadership is provided by the Finnish Nutrition Council, are: ${ }^{68}$

- Voluntary cooperation of the food industry to reduce salt; this included development and use of a salt substitute (PanSalt ${ }^{\circledR}$; described below);

- Mandatory "high salt" warning labels on foods whose sodium content exceeds defined limits;

- Mass media campaigns, which included broad dissemination of research exposing variation in sodium content amongst different brands of the same food product;

- Education and training programs for health professionals, home economics teachers, and caterers.

Much of the success of Finland's sodium reduction strategy has been attributed to their national labeling legislation, which was formulated by the Ministry of Trade and Commerce in collaboration with salt experts and the food industry. ${ }^{69}$ First, the country has implemented mandatory warning labels on high-sodium products, and this has had the effect of many highsalt products disappearing from the marketplace. ${ }^{70}$ To my knowledge, Finland is the only jurisdiction to have taken a regulatory approach to warning labels on food products. ${ }^{71}$ Second, products for which sodium content has been lowered may display a "reduced salt" claim, but only upon approval by a national authority. Third, products that contain PanSalt ${ }^{72}$ salt substitute may display the PanSalt ${ }^{\circledR} \operatorname{logo}$, which is widely recognized. Finally, for foods that have been identified as the most important contributors of salt to the national diet, products are required to declare salt content on their labels. Collectively, national labeling legislation has made it very easy for consumers to select healthy items. ${ }^{73}$

A unique leverage point for population-level dietary improvement in Finland is the catering industry. Since 1948, Finland has provided free lunch to all children in primary and secondary schools; these lunches are provided by public catering services, which were developed in Finland during the 1940s as part of health and social policies typical of Nordic countries at the time. ${ }^{74}$ Food shortages, coupled with the demographic fact of women (mothers) entering the paid labour force in large numbers, led to the emergence of child nutrition as a public health concern during and after the Second World War, thus instigating public catering. The program

68 Webster et al. 2011 op. cit.; Penney 2009 op. cit; Pietinen P, Mannisto S, Valsta LM, Sarlio-Lahteenkorva S. "Nutrition policy in Finland," Public Health Nutr 2010; 13:901-906.

69 Op. cit.

70 Penney 2009 op. cit.; Pietinen et al. 2010 op. cit.

71 World Health Organization 2010 op. cit.

72 PanSalt ${ }^{\circledR}$ (http://www.oriola.lv/en/Products/Pansalt/) is a low sodium / high potassium salt alternative that has the "taste, look, and texture" of common salt but contains only about half the sodium; it was developed in the 1980s in Finland and is available in Finland, Australia, and Philippines (and perhaps elsewhere) but does not appear to be available in Canada.

73 Webster et al. 2011 op. cit.

74 Raulio S, Roos E, Prattala R. "School and workplace meals promote healthy food habits," Public Health Nutr 2010; 13:987-992. 
continued after the war, and expanded in the 1970s to include subsidized meals in universities and workplace canteens. The expansion in the 1970s was partly prompted by demand created by the cohorts who had received free school lunches during the 1950s and 1960s, who were now entering university and/or the workforce. Another prompt was a recommendation from the Finnish Institute of Occupational Health that a proper meal at work be supplied, and this statement gradually worked its way into trade union agreements in the public and private sectors. Research has indicated that, although not everyone takes advantage of these meals, and although the meals do not quite contribute the 30 percent of daily caloric intake that they were intended to, consumption of these meals is nonetheless associated with better nutrition than eating elsewhere. ${ }^{75}$ The public administration and funding of these catering services, coupled with their normative role in Finnish society, provides a key leverage point for promoting population-wide nutrition, including reductions in sodium, through education and training of caterers. In terms of implications for Canada, the Finnish experience points to the value of identifying contained food procurement environments through which small changes may impact a large number of people. Examples include food service operations that are funded in whole or in part by provincial governments, such as hospitals, universities/colleges, schools (including vending machines), child-care settings, long-term care facilities, shelters, supportive housing, transition houses, recreation facilities, and community services, among others. One possible challenge to implementation is the trend towards privatization of food services in Canada, whereby franchises purchase the rights to sell within certain facilities. However, this challenge could be sidestepped by governments by making sodium reduction a requirement of the contract it signs with a private provider.

Collectively, Finland's efforts have resulted in significant population-wide sodium reduction and consequent health improvements. Baseline salt intake in Finland was very high (and therefore there was more room for improvement than in jurisdictions with lower baseline values, such as in Canada), but these high baseline values were what prompted coordinated action; first provincially in North Karelia, where a multi-component dietary intervention began in $1972,{ }^{76}$ and then nationally, such that Finland now has a well-developed national nutrition policy supported by a long history of epidemiological research on national diet and health, and a population that views nutrition as an important issue. However despite Finland's success, some scientists highlight that more could have been achieved; for example, Pietinen et al. feel that too much has been left to the consumer, such that Finland's nutrition policy is weaker than its economic or agricultural policy, which are characterized by a higher degree of regulation. ${ }^{77}$

\footnotetext{
75 Op. cit.

76 Puska P. "The North Karelia Project: from community intervention to national activity in lowering cholesterol levels and CHD risk," Eur Heart J 1999; 1(Suppl): S9-13.

77 Pietinen et al. 2010 op. cit.
} 
Overall, based on Finland's experience I draw the following recommendations for populationwide sodium reduction in Canada:

Policy recommendation: The federal government, with the support of provincial governments, should develop and implement mandatory national warning labels for high-sodium food products in Canada.

Policy recommendation: Provincial governments should, either individually or in coordination, provide support to conduct product comparisons to examine variation in sodium content between different brands of the same product, and assist with widespread publication and dissemination of findings.

Policy recommendation: Federal and provincial governments should coordinate to fund research into the investigation of potentially viable salt substitutes for widespread use. An example of a provincial initiative is the Quality Food for Health research funding opportunity, launched in May 2011 by Alberta Innovates - Bio Solutions with funding from ministries of Health and Wellness, Agriculture and Rural Development, and Advanced Education and Technology. Provincial governments should furthermore provide an incentive to food companies to switch to using the salt substitute, when available.

Policy recommendation: Provincial governments should, individually or in coordination, support the development and implementation of food procurement policies within food services environments that fall under provincial jurisdictions (e.g., schools, child care settings, recreation settings, hospitals and long-term care facilities)

\section{THE UNITED KINGDOM}

The need for dietary sodium reduction in the United Kingdom was recognized in the early 1990s, but national efforts got off to a slow start. In 1994, the Labour government appointed an independent advisory panel (the Committee on Medical Aspects of Food and Nutrition, COMA), which reviewed available evidence and recommended that salt intake be reduced to $6 \mathrm{~g} /$ day (equivalent to $2,358 \mathrm{mg} /$ day of sodium). In 1996, the Chief Medical Officer decided not to endorse these recommendations, due to opposition from the food industry. ${ }^{78}$ In response to this decision, a group of 22 scientific experts set up an action group (Consensus Action on Salt and Health, CASH) in protest. CASH was very active and was ultimately successful in a) engaging the food industry in sodium reduction (CASH managed to persuade a major supermarket and several food companies to reduce added salt); and b) convincing the government to reverse its 1996 decision and endorse COMA's original target of $<6$ g salt/day $(<2,358 \mathrm{mg}$ sodium/day). CASH thus played a crucial role in the UK sodium reduction strategy, and has inspired the development of similar groups elsewhere. ${ }^{79}$

\footnotetext{
78 He, MacGregor 2009 op. cit.

79 Op. cit.
} 
To oversee national sodium reduction, the UK Food Standards Agency (FSA) was formed. The multi-component sodium reduction strategy included sodium reduction in processed foods initiated voluntarily by companies, consumer education campaigns, front-of-package labeling, and restrictions on food marketing to children. In terms of voluntary reductions in processed foods, a decision was made to initially focus on supermarkets. Gradual reduction targets (i.e., 10-15 percent reduction at one time point, followed by an additional 10-15 percent reduction one or two years later; it was determined that a 10-15 percent reduction was not detectable to consumers) were set for more than 80 food categories. The UK's front-of-package labeling scheme includes, in addition to a display of nutrition information, a traffic light symbol which tells consumers at a glance whether a food is high (red), medium (amber) or low (green) in salt, sugar, fat, and saturated fat respectively. It is estimated that, though the scheme is voluntary, nutrition information is present on most (approximately 80 percent) foods, and the traffic light is present on approximately 40 percent of foods. ${ }^{80}$ Finally, since 2010 , there has been a restriction whereby foods that are high in fat, sugar, or salt as defined by the FSA cannot be advertised on television during children's or family-oriented programs. At other times, these foods may be advertised but may not use techniques that are attractive to children (e.g., licensed cartoon characters) nor make health claims. These restrictions pertain primarily to television; advertising in other media (e.g., digital media) is governed separately.

The impact of the UK sodium reduction efforts can be gleaned from population-based 24-hour urine data collected in 2000/01, 2005/06, and 2008. Compared to average salt consumption of $9.5 \mathrm{~g} /$ day $(3,734 \mathrm{mg} /$ day of sodium) in 2000/01, the 2005/06 data showed an average of $9.0 \mathrm{~g} /$ day of salt $(3,537 \mathrm{mg} /$ day of sodium), and the 2008 data showed a further reduction to $8.6 \mathrm{~g} /$ day of salt $(3,380 \mathrm{mg} /$ day of sodium). Thus a 10 percent reduction was achieved during an eight-year period. ${ }^{81}$ This ultimate evidence of reduction is consistent with data on discrete components of the program. For example, He and MacGregor report that, in response to targets set for food products, the sodium content of "most processed foods bought in supermarkets [was] reduced by $20-30$ percent in ... three years." 82 The consumer education campaign was associated with some improvements in consumer awareness and behaviour: between August 2004 and January 2005, there was a 32 percent increase in the number of people who claimed to make a special effort to cut down on salt, a 31 percent increase in the number who look at labeling to identify the salt content, and a 27 percent increase in the number who say that salt content would affect their decision to purchase a product. ${ }^{83}$

The UK experience showed that some population-wide sodium reduction may be achievable using a voluntary approach to product reformulation. However, it has become questionable whether further improvements are feasible (average intake, at $>8 \mathrm{~g}$ /day of salt, remains substantially higher than the WHO recommendation of $<5 \mathrm{~g}$ /day of salt), or even whether present reductions can be sustained. ${ }^{84}$ In 2010 , under a new government, leadership for population-level sodium reduction was shifted from the FSA to the Ministry of Health. ${ }^{85}$

\footnotetext{
80 Penney 2009 op. cit.

${ }^{81}$ World Health Organization 2010a op. cit.; Sodium Working Group 2010 op. cit; Penney 2011 op. cit.

82 He, MacGregor 2009 op. cit.

83 Penney 2011 op. cit.

84 Smith-Spangler et al. 2010 op. cit.

85 Penney 2011 op. cit.
} 
Shortly thereafter, the Ministry rejected a new set of fairly stringent recommendations set out by the National Institute for Clinical Excellence, which included the use of 'fiscal levers' and/or legislation to support production and sales of low-sodium food and healthier eating in general. It was also recommended that the traffic light labeling system be made mandatory, thereby resembling Finland's approach. Although these recommendations had broad public support, they were criticized by industry and ultimately rejected by the Department of Health as impractical.

Because the UK efforts (unlike efforts in some other jurisdictions) include restrictions on food marketing to children, and because such restrictions are also included in Canada's Sodium Working Group recommendations ${ }^{86}$ I comment briefly on them here. Restrictions on food marketing to children are viewed by many health researchers and organizations as an important component of efforts to improve population health related to diet (e.g., Alberta Policy Coalition for Chronic Disease Prevention [http://abpolicycoalitionforprevention.ca/] and the Chronic Disease Prevention Alliance of Canada [www.cdpac.ca/]). ${ }^{87}$ Although a reasonable evidence base exists to support such restrictions on health grounds ${ }^{88}$ the ethical case for a ban may in fact be the more effective rationale ${ }^{89}$ the province of Quebec is a case in point. Quebec has banned advertising to children since 1980 under sections 248 and 249 of the Consumer Protection Act..$^{90}$ The ban was challenged by industry, but ultimately upheld by the Supreme Court of Canada on the basis that children are unable to critically assess advertising, and thus advertising to children is not ethically defensible. ${ }^{91}$ One important challenge to the enactment of restrictions is that television advertising - which is the focus of the Quebec ban and arguably of most research literature to date - is only a small part of marketing to children. It is increasingly important to consider other media (e.g., internet or cellular-phone based promotion, games and contests, and in-store promotion intended to target children), which may be governed separately. ${ }^{92}$

${ }^{86}$ Sodium Working Group 2010 op. cit.

87 Elliott C. Assessing 'fun foods': nutritional content and analysis of supermarket foods targeted at children. Obes Rev 2008; 9:368-377.

88 Hastings G, McDermott L, Angus K, Stead M, Thomson S. The Extent, Nature and Effects of Food Promotion to Children: A Review of the Evidence. World Health Organization 2007. Available online:

http://www.who.int/dietphysicalactivity/publications/Hastings_paper_marketing.pdf; Cecchini M, Sassi F, Lauer JA, Lee YY, Guajardo-Barron V, Chisholm D. "Tackling of unhealthy diets, physical inactivity, and obesity: health effects and cost-effectiveness.," Lancet 2010 11/20; 376(9754):1775-1784.

89 Dutton DJ, Campbell NRC, Elliott C, McLaren L. "A ban on marketing of foods/beverages to children: the who, what, why, and how of a population health intervention," Can J Public Health in press.

90 Éditeur officiel du Québec. Consumer Protection Act. 1978:248-249.

91 Jeffery B. "The Supreme Court of Canada's Appraisal of the 1980 Ban on Advertising to Children in Quebec: Implications for "Misleading" Advertising Elsewhere," Loyola of Los Angeles Law Review 2006; 39(237).

92 Harris J, Pomeranz J, Lobstein T, Brownell KD. "A Crisis in the Marketplace: How Food Marketing Contributes to Childhood Obesity and What Can Be Done," Annu Rev Publ Health 2009; 30:211-25. 
Based on the UK experience, I draw the following recommendations for population-level sodium reduction in Canada:

Policy recommendation: Federal and provincial governments should enable the establishment of an action group of scientific experts (similar to CASH, Consensus Action on Sodium and Health, in the UK) and provide opportunity for the action group and government to frankly discuss the circumstances under which a regulatory approach to product reformulation may be feasible.

Policy recommendation: The population-based dietary monitoring system should include, in addition to population-based data on sodium intake, data on consumer knowledge and awareness of sodium and health, to enable evaluation of education campaigns.

Policy recommendation: The federal government, with the support of provincial governments, should restrict food marketing to children, on the grounds of both ethics (children cannot discern deceptive marketing) and health. Restrictions must include diverse media including, but not limited to, television.

\section{OTHER JURISDICTIONS}

Numerous other countries have implemented population-wide sodium reduction strategies; some examples and highlights follow. Strategies in Australia, New Zealand, South Africa, as well as Canada share in common the use of incentives to encourage companies to reduce sodium content of processed foods. ${ }^{93}$ In all of these countries, the incentive system is one part of a broader multi-component sodium reduction strategy. One of the more familiar incentive programs in Canada is the Health Check $^{\mathrm{TM}}$ program, while Australia has a similar program called Tick $^{\mathrm{TM}}$. Within these regimes, companies voluntarily make reductions to a certain level, in exchange for which they may purchase the right to display an endorsed logo on project packaging. Limitations of this approach are discussed below.

In France, sodium reduction efforts (which began in 2001) focused especially on sodium reduction in bread, based on data from a 1998/99 survey that identified bread (along with several other products) as a main contributor to sodium intake among the French population. Accordingly, in negotiations with food companies, special efforts were made to reach small independent bakeries and to negotiate with the flour industry. Overall, the French strategy (which also includes consumer education) has shown some success. The French salt industry reported a 15 percent reduction in the sales of salt to food manufacturers between 2001 and 2006 , and a five percent reduction in sales of household salt during this period. ${ }^{94}$ Based on analysis of a sample of food products in 2003 and a re-analysis of the same products in 2005, a decline in salt content was observed for cereals, some soups, and some cheeses. For bread and ready-to-eat meals, despite an emphasis on these products, salt content was found to be the same or had increased. However, as of 2006/07, one-third of bread bakers reported that they had reduced salt content since 2002. The cheese industry developed a new Code of Practice regarding the use of salt, and new lower-salt meat products have been developed. Despite some success, critics of the French program - as elsewhere - have bemoaned the undue influence of the food industry, which has thwarted more powerful government action.

93 Cobiac LJ, Vos T, Veerman JL. “Cost-effectiveness of interventions to reduce dietary salt intake," Heart 2010; 96:1920-1925.

94 Webster et al. 2011 op. cit. 
National sodium reduction efforts in Ireland, led by the Food Standards Agency of Ireland (FSAI) are modeled on the UK approach. ${ }^{95}$ As elsewhere, main components of the Irish strategy are sodium reductions in processed foods, product nutrition labeling, and education. ${ }^{96}$ Prior to the launch of the sodium reduction strategy, the FSAI had begun talks with the food industry about reducing the sodium content of certain foods. Initial reduction targets were set, and these have been reached. According to laboratory analysis used to monitor sodium content of food products, there has been a 10-15 percent reduction in salt content of white and brown breads, dry soup mixes, and dry sauce mixes. In terms of labeling, new legislation was developed for salt-related claims, such that there are now defined limits that companies must achieve to claim "reduced salt," "low salt," "very low salt," and "salt-free". Consumer awareness campaigns have been run, and consumer interviews conducted after one campaign indicate that over 50 percent of those surveyed said they had changed, or plan to change, their salt intake. National data collected during 2007-2010 including urinary analysis indicate daily salt consumption of $10.4 \mathrm{~g} /$ day for men $(4,087 \mathrm{mg} /$ day of sodium) and $7.4 \mathrm{~g} / \mathrm{day}$ for women $(2,908 \mathrm{mg} /$ day of sodium $)$, which are well above the $6 \mathrm{~g} /$ day of salt $(2,358 \mathrm{mg} /$ day of sodium $)$ target set by the FSAI, and the $5 \mathrm{~g} /$ day of salt $(1,965 \mathrm{mg} /$ day of sodium) target set by the WHO; however subsequent data on sodium intake, in response to efforts taken, do not appear to be yet available.

The preceding paragraphs focus on countries with multi-component sodium reduction strategies, which is the norm in the developed world, and which is in line with the WHO model. There are some examples of single-component programs that have shown some effect. In both Japan and Portugal, very high levels of sodium intake and hypertension prevalence prompted action in the form of education campaigns. Portugal's campaign, which entailed intense publicity around three sodium-related health messages, was evaluated using a controlled trial design which showed a population-level effect in the intervention region: salt intake and blood pressure improved such that there was a leftward shift in the population distribution in that community. ${ }^{97}$ In Japan, the government implemented a sustained public information campaign in the 1960s to encourage the population to reduce dietary sodium intake. At the time, stroke mortality in Japan was among the highest in the world, and salt consumption was as high as $18 \mathrm{~g} /$ day $\left(7,074 \mathrm{mg} /\right.$ day of sodium) in certain northern regions. ${ }^{98}$ During the following decade, salt intake declined from an average of $13.5 \mathrm{~g} / \mathrm{day}(5,306 \mathrm{mg} / \mathrm{day}$ of sodium) to $12.1 \mathrm{~g} /$ day $(4,755 \mathrm{mg} /$ day of sodium), and in the northern regions from $18 \mathrm{~g} / \mathrm{day}$ (7,074 $\mathrm{mg}$ /day of sodium) to $14 \mathrm{~g} /$ day $(5,502 \mathrm{mg} /$ day of sodium). There was a parallel drop in blood pressure in adults and in children, and an 80 percent drop in stroke mortality was observed. That there were large increases in other risk factors (fat intake, cigarette smoking, alcohol consumption, and BMI) suggests that the improvements to health outcomes reflect at least in part reductions in sodium consumption. ${ }^{99}$ Subsequent to the end of the campaign, salt consumption levels appeared to be rising again (http://www.worldactiononsalt.com/evidence/ population_studies.htm).

\footnotetext{
95 Op. cit.

96 Op. cit.; He, MacGregor 2009 op. cit.

97 Forte JG, Pereira Miguel JM, Pereira Miguel MJ, de Padua F, Rose G. "Salt and blood pressure: a community trial," J Hum Hypertens 1989; 3:179-184.

98 Webster et al. 2011 op cit; He, MacGregor 2009 op. cit.

99 Webster et al. 2011 op cit.
} 
Although the data from Portugal and Japan suggest that some sodium reduction is possible in response to public education, significant caveats of this approach must be noted. First, populations in both Japan and Portugal had extremely high baseline sodium levels, and therefore one could argue that an observed improvement was more likely than in populations with lower baseline values, simply because there is more room for improvement. Also, as acknowledged by the authors, educational initiatives alone may be uniquely suited to certain types of societies - i.e., those in which the population is close-knit and largely rural - which was true for both countries at the time. Finally, even if educational campaigns were successful in terms of changing consumer behaviour (which, generally speaking, is arguable, in the absence of a supportive environment), this approach would have limited impact in Canada because, as noted, most of our sodium comes from processed foods over which individuals have limited control.

From the preceding paragraphs, where initiatives in various jurisdictions are described, I identified one recommendation that seems suitable for a Canadian sodium reduction strategy, based on the French experience.

Policy recommendation: Federal and provincial governments should coordinate to fund research to identify those foods that constitute significant contributors to sodium consumption in the population, and focus product reformulation efforts on those. In the Alberta population, for example, meat and dairy products are potential targets.

\section{USA (NATIONAL, STATE, AND MUNICIPAL/COUNTY JURISDICTIONS)}

Sodium reduction efforts are currently underway in the US, and these initiatives may be particularly informative for provincial governments because they have involved national, state, and local (i.e., county) levels of government. I start by describing the national context. Although nationally there has been consistent advice to the US population to reduce dietary sodium since the 1980s, little in the way of concrete action occurred until the 2000s. In 2000 a large meeting organized by the National Heart, Lung, and Blood Institute was held, from which a conclusion emerged that the US needed a national population-level sodium reduction strategy. It appears that action subsequently stalled again, until 2005 when the Center for Science in the Public Interest (an independent health advocacy organization) was formed and sent a petition to the FDA calling for tougher regulations on salt. 2005 was also the year that the Institute of Medicine released their recommendations for intake of sodium (among other nutrients), i.e., the recommended Tolerable Upper Intake Limit (UL) of 2,300 mg/day of sodium. In 2007, the American Medical Association published a report calling for major reduction of salt content in processed and restaurant foods. ${ }^{100}$ The Institute of Medicine subsequently established an ad hoc committee to make recommendations for ways to achieve their recommended dietary guidelines $(<2,300 \mathrm{mg} /$ day of sodium).

${ }^{100} \mathrm{He}$, MacGregor 2009 op. cit. 
Interestingly, the US national sodium reduction strategy is being coordinated by a local entity, the New York City Health Department (http://www.nyc.gov/html/doh/html/cardio/cardio-saltinitiative.shtml). Beginning in 2008, a coalition of cities, states, and national health organizations throughout the US, led by the NYC Department of Health and Mental Hygiene, engaged the food industry towards developing a voluntary framework for sustained, gradual reductions in the sodium content of foods. ${ }^{101}$ The initiative, called the National Salt Reduction Initiative (NSRI), has a goal of reducing Americans' salt intake by 20 percent over five years. The NSRI is described as "an unprecedented public-private partnership" whereby companies commit to making progress towards sodium content guidelines (targets have been set for over 60 categories of packaged food and at least 25 categories of restaurant food).

In February 2010, by way of encouraging national sodium reduction being led by New York City Health, the Institute of Medicine recommended that, "all state and local health jurisdictions immediately begin to consider developing a portfolio of dietary sodium reduction strategies that make the most sense for early action in their jurisdiction." 102 Local efforts have begun and/or are under consideration in New York City, the state of Massachusetts and in Los Angeles County in California. In line with the IOM encouragement, Los Angeles County developed their portfolio of strategies, from which a food procurement policy was deemed the most promising. The proposed policy would require food service venues controlled by the County of Los Angeles to meet specified nutrition standards, including limits on sodium content. ${ }^{103}$ The feasibility and potential impact of the proposed policy were analyzed in two recent publications. ${ }^{104}$ Gase et al. conducted interviews with representatives of three groups: County departments with food services, non-County entities with food services, and organizations that catered food to County departments. ${ }^{105}$ Interviews focused on facilitators of and barriers to the proposed food procurement policy. Facilitators identified were:

- Organizations do have the authority to impose nutrition standards, provided they are stricter than federal or state regulations;

- Nutrition was identified as a high priority in most organizations, and in fact several county departments had staff dietitians already on staff, who expressed willingness to support such a policy; and

- There is opportunity to build on existing policy (e.g., nutrition standards or policies already in place), which would facilitate implementation. In some cases this would be reasonably straightforward, e.g., changing wording around sodium standards from "recommended" to "required."

\footnotetext{
${ }^{101}$ Gase LN, Kuo T, Dunet DO, Simon PA. "Facilitators of and barriers to implementing a local policy to reduce sodium consumption in the County of Los Angeles government, California, 2009," Prev Chron Dis 2011; 8(2).

102 Op. cit.

${ }^{103}$ Op. cit.

${ }^{104}$ Op. cit; Gase LN, Kuo T, Dunet D, Schmidt SM, Simon PA, Fielding JE. "Estimating the potential health impact and costs of implementing a local policy for food procurement to reduce the consumption of sodium in the County of Los Angeles," Am J Public Health 2011; doi:10.2105/AJPH.2011.300138

${ }^{105}$ Gase et al. 2011a op. cit.
} 
However several potential barriers were identified; these were:

- Unique features of food service environments. Different organizations differ in their existing food standards/policies, populations served, and contracts currently in place and thus the notion of a one-size-fits-all policy met with resistance;

- Perception that lower sodium foods may be costly and less easily available;

- Challenges faced by organizations that rely on donations from food and beverage companies;

- Concern about longer preparation time and lower profit margin of lower-sodium foods;

- Concern about the complexity of food service environments (e.g., serving meals to multiple clients in multiple formats, 24 hours/day; use of multiple sub-contractors), which could make it difficult to implement and monitor a policy;

- Perception of low demand for healthy (including lower-sodium) foods,

- Perception that lower-sodium foods do not taste as good and therefore clients will go elsewhere;

- Several vendors prefer to use prepackaged items, for food safety reasons or because of lack of cooking/preparation facilities, and the vendor has little to no control over the sodium content in these items;

- Vendors expressed limited knowledge and experience in operationalizing sodium standards, indicating that specific guidelines and training would be needed; and

- Complexities introduced through contracts. Organizations cannot change existing contracts, and new contracts have a lengthy review period.

Overall, notwithstanding the barriers, the facilitators identified were promising. Accordingly, Gase et al. concluded that, "developing or changing policies for procuring food represents a potentially feasible strategy for reducing sodium consumption in food service venues controlled by the County of Los Angeles." 106 They also estimated ${ }^{107}$ that this initiative would yield health benefits and health-care savings: for example, it was estimated that a particular iteration of the policy focused on six settings (child care, seniors meals, buffet cafeterias, mobile trucks, hospital cafeterias, and county government cafeterias) would result in a daily average sodium reduction of $233 \mathrm{mg}$ for adults (a $304 \mathrm{mg}$ reduction among children in the child-care setting), an average reduction in systolic blood pressure of $0.71 \mathrm{~mm} \mathrm{Hg}, 388$ fewer cases of uncontrolled hypertension, and direct health care savings of $\$ 629,724$. Although the estimated costs of the program ranged from $\$ 227,753$ to $\$ 1,723,539$, the majority of representatives interviewed believed that these are predominantly start-up costs, and costs thereafter would be much less and quite manageable.

\footnotetext{
${ }^{106}$ Op. cit.

${ }^{107}$ Gase et al. 2011 b op. cit.
} 
Food procurement policy, shown to be feasible and potentially impactful in Los Angeles County, would appear to be highly pertinent to the provincial context. Gase et al. recommend that the settings most suited to an effective procurement policy are those in which: 1) multiple meals are served to the same customers over a period of weeks or months; 2) meals with high sodium content are currently served; and 3) the population served has a moderate to high prevalence of hypertension. ${ }^{108}$

Policy recommendation: Provincial governments should, individually or in coordination, support the development and implementation of food procurement policies within food services environments that fall under provincial jurisdiction (e.g., schools, child care settings, recreation settings, hospitals and long-term care facilities).

In addition to the development and dissemination of nutrition guidelines (which is already underway in some provinces), support should entail:

Policy recommendation: Moving from optional guidelines to mandatory policy for sodium content of food served/sold.

Policy recommendation: Working collaboratively with food services environments to ensure that policy is feasible, and that adequate support is provided for its implementation.

Policy recommendation: Subsidizing, at least initially, the costs of lower-sodium items being purchased to meet sodium targets, for food services that need it.

\section{DIETARY SODIUM REDUCTION IN CANADA: EXISTING INFRASTRUCTURE}

Against the backdrop of the discussion of initiatives in other jurisdictions above, I now return to Canada and consider efforts already in place. I divide the following discussion into two sections. First I focus on monitoring; second, I describe pertinent intervention efforts historically and currently.

108 Gase et a. 2011a; $2011 \mathrm{~b}$ op. cit. 


\section{a) Monitoring}

In Canada, our main source of data on dietary sodium intake (and in fact diet in general) is the 2004 Canadian Community Health Survey, a population-based health survey which included dietary intake data gathered via a 24-hour dietary recall ${ }^{109}$ from a representative sample of Canadians of all ages. Historical data on sodium intake specifically, and diet in general, for Canadians are limited; in fact, the CCHS 2.2 is the first national nutrition survey since the 1970-72 Nutrition Canada Survey. The absence of historical data makes it difficult to monitor trends over time either nationally or by province (I note, however, that another national nutrition survey is planned for 2015). A further complication is introduced when consecutive surveys are based on different methods; for example, if a different sampling frame is used, or a different technique is used to gather dietary data, or variables to indicate dietary correlates change over time. Because of the importance of health survey data for monitoring any sodium reduction interventions, it seems important to recommend the development of a populationbased dietary monitoring system that is consistent over time. This could be done federally (i.e., ensuring continuity of the CCHS nutrition infrastructure), or provincially.

Provincial nutrition surveys have been undertaken. During the 1990s, Health Canada's Bureau of Nutritional Research worked with provinces to carry out population-based nutrition surveys; the surveys had a target population of adults age 18-74, used a probability sampling strategy (cluster-stratified random sample), and assessed diet using a 24-hour dietary recall and a modified food frequency questionnaire. While data for some provinces is available, the Alberta Nutrition Survey data do not appear to have been published, ${ }^{110}$ other than in a MSc thesis. ${ }^{111}$ Nonetheless, the fact that these provincial surveys were conducted suggests that the provinces have experience and infrastructure to carry out similar data collection in the future, perhaps in conjunction with the federal health ministry.

Earlier I pointed out that surveillance capacity must be in place to allow for the evaluation of policy impact. Now, I expand on recommendations for monitoring. Although the CCHS 2.2 provides excellent data, there are two notable limitations with current data resources. First, although the 24-hour dietary recall technique is widely used and is designed to yield information that is as accurate as possible (e.g., a five-step approach is used to capture frequently forgotten foods and to maximize precision of estimates for food/beverage type and quantity), ${ }^{112}$ the reported nature of the data means that it is impossible to entirely eliminate errors and bias in reporting. Also, the dietary estimates gathered through the 24-hour recall do not include salt added at the table or during cooking, which is very difficult to quantify in surveys. For these reasons, the gold standard for measurement of sodium intake is 24-hour urinary excretion (Elliott \& Brown 2007). ${ }^{113}$ The population-based dietary monitoring system should thus incorporate periodic micronutrient analysis based on 24-hour urine samples.

\footnotetext{
109 Garriguet 2007 op. cit..

${ }^{110}$ Dolega-Cieszkowski JH, Bobyn JP, Whiting SJ. "Dietary intakes of Canadians in the 1990s using populationweighted data derived from the provincial nutrition surveys," Appl Physiol Nutr Metab 2006; 31:753-758; Vatanparast H, Dolega-Cieszkowski JH, Whiting SJ. "Many adult Canadians are not meeting current calcium recommendations from food and supplement intake," Appl Physiol Nutr Metab 2009; 34:191-196.

${ }^{111}$ Ransome 2001 op. cit.

112 Garriguet 2007 op. cit.

${ }^{113}$ Elliott P, Brown I. Sodium intakes around the world. Background document prepared for the Forum and Technical meeting on Reducing Salt Intake in Populations (Paris 5th-7th October 2006). Geneva: World Health Organization, 2007.
} 
Policy recommendation: A system for population-based dietary monitoring should include a) a survey-based method of gathering dietary intake data (e.g., 24-hour recall) as well as b) a 24-hour urine sample, which is considered the gold standard for accurate assessment of sodium consumed from all sources.

The second limitation of existing Canadian dietary data stems from characteristics of other databases that are used in conjunction with the CCHS. Specifically, analysis of diet involves taking the data from the CCHS's 24-hour recall and coding it against existing food classification and nutrient profile schemes ${ }^{114}$ developed by Health Canada and Statistics Canada. ${ }^{115}$ For example, a respondent in the CCHS reports that he/she consumed a certain amount of orange juice, and then nutrient information for that item is taken from the Canadian Nutrient File, which contains nutrition information (macronutrients, micronutrients) for orange juice. A limitation of this system as it currently stands is that nutrient content (including sodium) of food products is aggregated by food category within the Canadian Nutrient File. For example, the sodium content of canned, condensed tomato soup is estimated based on a representative or averaged product, such that the sodium intake assigned to an individual from this product will be the same regardless of whether that individual consumed a generic brand of tomato soup or a special reduced-sodium variety. The absence of this information in the Canadian Nutrient File is an important limitation because it dilutes true variation in diet. The (missing) information may be particularly important for understanding socioeconomic inequalities in sodium consumption specifically, and in diet generally, ${ }^{116}$ to the extent that persons of lower socioeconomic circumstances purchase and consume the less expensive brand or variety of a product (which is probably poorer nutritionally, including higher in sodium), analyses using the current database will underestimate any socioeconomic inequities in intake.

I acknowledge the complex and dynamic nature of the food supply; frequent introduction of new products and reformulation of existing products to take advantage of marketing opportunities present challenges to maintaining a current and comprehensive database. Nonetheless, a database that is as comprehensive and up-to-date as possible is essential for ongoing monitoring of population trends and evaluation of any intervention efforts to reduce population-wide sodium intake. There is opportunity to improve it by accommodating different brands or types of the same food category, and provinces could make a significant contribution by leading the way in refining the national nutrient content database, and/or by lobbying for this to be done at a federal level.

Policy recommendation: The federal government, with the support of provincial governments, should refine the Canadian Nutrient File, to enable a more nuanced analysis of sodium, which is known to vary by brand within the same product.

\footnotetext{
${ }^{114}$ Canadian Nutrient File - About Us. Available online at http://www.hc-sc.gc.ca/fn-an/nutrition/fiche-nutridata/cnf_aboutus-aproposdenous_fcen-eng.php

${ }^{115}$ Riciutto, Tarasuk 2007 op. cit.; Fischer et al. 2009 op. cit.

${ }^{116}$ Tarasuk et al. 2010 op. cit.
} 
It is important to ensure efficient use of resources and maximize the utility of data gathered in the long run. To inform development of the population-based dietary monitoring system, it would be prudent to first conduct a systematic scan of what data are already available (federally and provincially), and for which surveillance infrastructure already exists (e.g., CCHS 2.2; the provincial nutrition surveys of the 1990s). Also, the importance of monitoring is not limited to dietary sodium; ideally a population-based monitoring system would include a range of variables indicating health outcomes and determinants of health.

Policy recommendation: The population-based dietary monitoring system should build on (not duplicate) existing provincial surveillance, and should incorporate a range of information on health outcomes and determinants of health, not just diet and sodium.

\section{b) Dietary sodium reduction efforts in Canada}

In this section, I describe efforts in Canada to reduce dietary sodium in individuals and populations. Generally speaking, concern about excess dietary sodium intake, and efforts to reduce intake in individuals and populations, are relatively recent phenomena, dating to the 1980s and later.

In describing what has been done at the provincial level, I focus on Alberta because it is the provincial response with which I am most familiar. In Alberta, provincial nutrition guidelines have been developed, ${ }^{117}$ which include but are not limited to sodium. The guidelines are aligned with Canada's Food Guide and have been tailored to different age groups and settings. The Alberta Nutrition Guidelines for Children and Youth (ANGCY), first released in 2008, provide detailed information, recommendations, and practical suggestions for creating supportive nutrition environments in child-care, schools, and recreation settings. More recently, in 2011 Alberta Nutrition Guidelines for Adults were released; these contain information, recommendations, and practical suggestions for nutrition in the workplace. Both sets of guidelines are based on a rating system wherein foods are classified as "choose most often," "choose sometimes," or "choose least often," and recommendations are provided as to the proportion of foods from each category that should be available in a given setting.

It should be noted that these efforts differ (at present) from contained food services efforts elsewhere (e.g., Finland, LA County) in that adherence to the guidelines is not regulated or mandated; in fact the guidelines for child-care settings are explicitly identified as "optional." This is not to say that the guidelines cannot be operationalized in a regulatory manner. In the ANGCY document, an example is provided of one child-care facility that told parents/caregivers: "... If you do not include the four main food groups in your child's lunch the daycare is responsible to supplement the lunch and there will be additional costs," thereby introducing a disincentive that may be beneficial from a health promotion point of view. That said, whether and to what extent the guidelines are adopted is at the discretion of each facility, and facilities may differ greatly in terms of resources available and the extent to which nutrition is a priority. The guidelines are still relatively new, and their impact on diet is not yet known. However, it is likely that - in the absence of larger-scale food product reformulation efforts or any regulation - the impact of this excellent resource will be limited.

${ }^{117}$ Healthy Alberta Home Page. Available online at www.healthyalberta.com 
Nationally, perhaps the first indication of recognition of a need for sodium reduction was the decision, on the 1982 iteration of Canada's Food Guide, to encourage Canadians to limit their intake of salt, as well as fat and sugar. Canadians were encouraged to "select and prepare foods" in a way that limited intake of these nutrients. ${ }^{118}$ The inclusion of the word "prepare" indicates some focus on discretionary use of salt (i.e., salt added at the table or during cooking). Although this may have been important in the early 1980s, we now know that discretionary salt presently constitutes only a very small proportion of sodium consumed, and therefore should not be the primary target of a population-wide sodium reduction intervention.

Subsequent national sodium reduction efforts appeared in the late 1990s. These more recent efforts illustrate growing recognition of the need to involve the food industry. In 1999, the Heart and Stroke Foundation of Canada (HSFC) launched the Health Check ${ }^{\mathrm{TM}}$ program, a voluntary initiative whereby grocery and menu items meeting certain nutrition criteria (including reduced sodium) are permitted to display the Health Check $^{\mathrm{TM}}$ symbol, which conveys to consumers that the product is a healthier alternative. ${ }^{119}$ Nutrition labeling (including the Nutrition Facts Table, which provides information on 13 core nutrients [including sodium] and the percent of recommended daily value for each nutrient) was introduced in 2003 and became mandatory for all pre-packaged foods in December 2007. Other efforts to educate and inform consumers have been undertaken by non-governmental organizations. For example, Hypertension Canada and the Canadian Stroke Network both developed websites (www.lowersodium.ca and www.sodium101.ca respectively) that provide information on sodium and health for the public (both websites) and health professionals (Hypertension Canada's website). The Canadian Hypertension Education Program, which was introduced in 1999 and is now part of Hypertension Canada, provides information and recommendations to health professionals about prevention as well as treatment/management of hypertension. The Centre for Science in the Public Interest (http://www.cspinet.org/canada/) publishes information on the nutritional content of food products, to help consumers make healthy choices among brands.

Attention to dietary sodium reduction increased significantly in the latter half of the last decade. 2006 saw the appointment of the first Canadian Chair in Hypertension Prevention and Control (Dr. Norm Campbell), sponsored by CIHR and partner organizations. ${ }^{120}$ In 2007, Hypertension Canada developed a policy statement on sodium that contained recommendations to federal government to initiate a national salt reduction strategy. ${ }^{121}$ That same year (2007), the federal Minister of Health (Tony Clement) established the national Sodium Working Group, which was tasked with developing a sodium reduction strategy for Canada.

\footnotetext{
${ }^{118}$ Canada's Food Guides from 1942 to 1992. Available online at http://www.hc-sc.gc.ca/fn-an/food-guidealiment/context/fg_history-histoire_ga-eng.php

${ }^{119}$ Several health-related product endorsements now exist in the food marketplace, both non-profit (e.g., the Whole Grains Council stamp) and industry-driven (e.g., Loblaws' Guiding Stars logo). I highlight Health Check because it was one of the first in Canada and is perhaps the most widely known among the public.

${ }^{120} \mathrm{He}$, MacGregor 2009 op. cit.

${ }^{121}$ Sodium Working Group 2010 op. cit.
} 
The Sodium Working Group (SWG) included 25 members from various stakeholder communities (i.e., food manufacturing, food services, health-focused NGOs, scientific community, consumer advocacy groups, health professional organizations, and various government departments and agencies) and was chaired by a representative from Health Canada. ${ }^{122}$ During a two-year period, the group worked to develop recommendations within a three-pronged approach: i) voluntary reduction of sodium levels in processed food products and foods sold in food services establishments; ii) education and awareness of stakeholders (consumers, industry, health professionals, etc); and iii) research. A fourth aspect, monitoring and evaluation, transcends the others. The recommendations are outlined in the group's final report, which was released in July 2010. ${ }^{123}$ Along with recommendations, the SWG set intake goals: the interim intake goal is for population average intake to be $2,300 \mathrm{mg} /$ day (by 2016), and the ultimate intake goal is for most (>=95 percent) of the population to have a sodium intake below 2,300 mg/day. As noted previously, 2,300 mg/day of sodium is the tolerable upper intake recommended by the U.S. Institute of Medicine. ${ }^{124}$

It is important to clarify that the three-pronged approach (voluntary reductions in processed foods, education, and research) was set out at the initiation of the SWG's two year period of work, and was built into the group's mandate and terms of reference. ${ }^{125}$ The fact that this was set at the beginning means that the group had no flexibility to identify a regulatory approach to the reduction of sodium in processed foods, even if empirical research and expert opinion supported this approach (which is the case). By way of working around this restriction, the specific description of the voluntary reduction prong is a "structured voluntary approach," wherein "structured" refers to the development and publication of sodium reduction targets for foods, defined timelines for achieving targets, a mechanism for public commitment to the targets by companies, a plan for monitoring progress by a body other than the food industry, and a plan for independent evaluation of the success of the program, with the option of taking stronger measures as necessary depending on progress (italics added). ${ }^{126}$

Shortly after the release of the SWG's 2010 report, implementation activities began, such as setting sodium reduction targets for specific foods. However, the status of the national sodium reduction strategy has since become uncertain. In February 2011, the federal government announced the dismantling of the Sodium Working Group, in favour of a Food Regulatory Advisory Committee (FRAC). Although the dismantling of the SWG was not entirely unexpected given that it had served its purpose and produced the national strategy, concerns were nonetheless expressed about the viability of a national sodium reduction strategy in light of FRAC's significant ties to the food industry (Jeffery 2001). ${ }^{127}$ Following the 2010 release of

\footnotetext{
122 Op. cit.

123 Op. cit.

${ }^{124}$ Institute of Medicine 2005 op. cit.

${ }^{125}$ Sodium Working Group 2010 op. cit.

${ }^{126}$ Op. cit.

${ }^{127}$ Jeffrey B. Technical brief of Bill Jeffrey, LLB, National Coordinator, Centre for Science in the Public Interest, before the Hearing on Healthy Living of the House of Commons Standing Committee on Health, February 3, 2011, Ottawa.
} 
the SWG final report, provinces were tasked with developing a plan for how they would achieve the targets laid out in the Sodium Reduction Strategy. These plans were laid out in a report titled "Reducing the sodium intake of Canadians: Federal, Provincial and Territorial actions taken and future directions," 128 which was set to be released in November 2011 at a meeting of the Health Ministers in Halifax; however, the federal Health Minister declined to endorse it, ${ }^{129}$ stating that although "we're serious about the issue of sodium," concern was expressed that the "structured voluntary approach" to product reformulation might be "too structured," causing companies to opt out altogether. The 2011 report, because it was not approved, is not publicly available.

Notwithstanding the uncertainty of national sodium reduction in Canada, it is important to recognize that a great deal of work went into developing the recommendations outlined in the SWG's final report, ${ }^{130}$ and that there is value in scrutinizing them towards identifying policy options for provinces. Although most of the SWG's recommendations pertain to the federal jurisdiction, there are areas in which provincial efforts are possible and/or for which provincial leadership could potentially support national efforts. Below I list pertinent recommendations from the SWG report that are not identified elsewhere in this paper.

Policy recommendation: Federal and provincial governments should coordinate to ensure that sodium reduction targets and progress towards targets be posted on websites of all pertinent government ministries that would be involved in a holistic provincial sodium reduction strategy.

Policy recommendation: The federal government, with the support of provincial governments, should amend the Food and Drug Regulations to ensure that the serving sizes used in the Nutrition Facts table (NFT) are as uniform as possible, to facilitate the comparison of sodium levels in similar foods, and to align with serving sizes assumed by Canada's Food Guide.

Policy recommendation: The federal government, with the support of provincial governments, should amend the Food and Drug Regulations to change the basis of the Daily Value (DV) for sodium in the Nutrition Facts table (NFT) from 2,400 mg to $1,500 \mathrm{mg}$ to reflect the IOM's recommended Adequate Intake (AI) level.

Policy recommendation: Provincial governments should, either individually or in coordination, make applicable changes to provincial regulations to require the onsite disclosure of nutrition information in a consistent and readily accessible manner for standardized menu items prepared and assembled on-site at restaurants and food services establishments.

\footnotetext{
${ }^{128}$ Schmidt S. "Feds refused proposed plan to cut sodium," Calgary Herald. December 12, 2011.

${ }^{129}$ Op. cit.

${ }^{130}$ Sodium Working Group 2010 op. cit.
} 
Policy recommendation: Provincial governments should, either individually or in coordination, make applicable changes to provincial regulations to update the food additive approval process and standards of identity for foods while maintaining microbial safety.

Policy recommendation: The federal government, with the support of provincial governments, should review and update Canada's Food Guide to increase the prominence and effectiveness of advice regarding sodium and calories. It is essential that this occur in an impartial manner, i.e., at arm's length from industry.

Policy recommendation: Federal and provincial governments should coordinate to fund all types of research pertaining to population-wide dietary sodium reduction (i.e., sodium physiology, research into microbial safety and food technology issues, and population and public health research, including evaluations of programs and policies).

Policy recommendation: Provincial governments should, either individually or in coordination, support continued emphasis on reduced-sodium food preparation curriculum within pertinent training programs at provincial institutions (an example in Alberta is the Professional Cooking program at the Southern Alberta Institute of Technology).

\section{KEY ISSUE: CAN A VOLUNTARY APPROACH WORK?}

I conclude with a discussion of an issue that figures prominently in sodium reduction efforts in Canada and other liberal democratic jurisdictions (e.g., the UK and the US): whether a voluntary approach to food product reformulation can achieve sodium reduction targets. Although there is agreement that population-wide sodium reduction in wealthier countries must involve reductions to sodium added to foods at processing (since this is where most of our sodium comes from), whether this should occur on a voluntary (at the will of individual companies) or mandatory (regulations imposed by government) basis is more contentious. Most jurisdictions have adopted a voluntary approach to product reformulation; however, Canadian and international experts have acknowledged that regulatory approaches may be necessary to achieve stated goals. ${ }^{131}$

\footnotetext{
${ }^{131}$ World Health Organization 2007 op. cit.; Sodium Working Group 2010 op. cit.
} 
There are significant limitations of a voluntary approach to product reformulation as currently executed. First, there are financial disincentives to companies for participating. As noted, sodium's multiple functions (including preservation and taste- and texture-enhancement), coupled with its low cost, make it highly valuable to food companies. It stands to reason, therefore, that only a subset of companies is going to risk financial and commercial viability to reduce sodium, if it is optional to do so, and this would result in limited, if any, impact on population-level sodium intake. As an illustration of the financial risks associated with voluntary sodium reduction, Campbell's ${ }^{\circledR}$ soup company recently announced that, in the US, it will re-introduce sodium into its products, in response to "flagging financials" that followed their high-profile, large-scale sodium reduction via product reformulation announced in February 2010. ${ }^{132}$ The change does not appear to pertain to Campbell's soup in Canada. ${ }^{133}$

Second, even among those companies that opt in, health impact may be limited. An example is programs through which companies can make nutrient profile improvements in exchange for the privilege of displaying a trademarked health logo. Although such programs are wellintentioned and are to be commended for taking on the complex task of developing nutrition criteria for use by food companies, ${ }^{134}$ concern has been expressed about the leniency of the criteria required to display the logo, and the implications of that leniency for public health impact. ${ }^{135}$ In particular, it has been demonstrated that products with logos may still contain high levels of nutrients deemed 'unhealthy' such as sodium and sugars, ${ }^{136}$ such that in the past some products of questionable nutritional quality have displayed healthy choice logos. ${ }^{137}$ Concern has furthermore been expressed that the logo conveys to consumers that a product is healthy in an absolute sense and should be selected, when in fact the logo more accurately indicates that a product is relatively more nutritious than other non-nutritious products within the same food category. ${ }^{138}$ Finally, companies may have to pay a fee to participate in these programs ${ }^{139}$ which, even if modest, nonetheless poses an additional disincentive to companies for whom economic viability is the main concern.

Third, in addition to a weak overall impact for the population, a voluntary approach to product reformulation may contribute to widening socioeconomic inequalities in health. This is an important consideration for population health, ${ }^{140}$ which is concerned not just with overall health metrics (e.g., population mean or prevalence), but also with the discrepancy in health between

\footnotetext{
${ }^{132}$ Weeks C. "Campbell's adding salt back to its soups," The Globe and Mail, July 14, 2011.

${ }^{133}$ Gifford-Jones W. "Can't see the salt for the trees: consumers' taste buds go against a company's best intentions," Toronto Star, July 23, 2011.

${ }^{134}$ Maloff B. Health Check program (letter). CMAJ 2008;178:1187.

${ }^{135}$ Freedhoff Y. Health Check program (letter). CMAJ 2008;178:1188; Jeffrey B. Health Check program (letter). CMAJ 2008;178:1187-1188; Nestle M. Re-thinking Heart-Check labeling programs (letter). CMAJ, published online February 4, 2008.

${ }^{136}$ Freedhoff 2008 op. cit.; Jeffrey 2008 op. cit.

${ }^{137}$ Truscott A. Checking up on Health Check (news). CMAJ 2008;178:386-387.

138 Jeffrey 2008 op. cit.

${ }^{139}$ Truscott 2008 op. Cit.

${ }^{140}$ CIHR Institute of Population and Public Health op. cit.
} 
those of higher and lower socioeconomic resources. When sodium reduction is voluntary, and only some companies opt in, the result will be higher and lower sodium versions of the same product, and it is likely that the higher sodium version will be cheaper. Consumers in general, but especially those with limited economic resources, are influenced by price when selecting and purchasing foods. If costlier foods with low sodium are differentially consumed by the wealthier members of the population, and the poorer segments continue to consume less expensive, higher-sodium products, inequalities in sodium consumption (and thus inequalities in sodium-related health outcomes) may ensue. There are data to suggest that this may occur. Ricciuto et al. compared the trans fat content and prices of margarines in major supermarkets in Toronto prior to (in 2002) and after (in 2006) the implementation of national labeling regulations that required companies to disclose trans fat content of products. ${ }^{141}$ Overall, it was found that trans fat content in margarines decreased. However, the decrease was not uniform: in both 2002 and 2006, margarines low in trans fats or that were trans fats-free cost significantly more than other margarines, and the relationship between price and trans fat content was stronger in 2006 than in 2002. In other words, mandatory nutrition labeling, in the absence of regulations around product reformulation, resulted in an increased price differential between the healthier and the less healthy product, in terms of trans fats. In contrast, an outright ban on trans fats in Denmark (under which all products had to comply with set maximum levels) resulted in no noticeable effect on price or availability of foods that previously contained high trans fats. Ricciuto et al. concluded that "there may be limited potential to improve the trans fat content of low-cost products through a voluntary approach," and it is reasonable to assert that this is also true for sodium. ${ }^{142}$

In light of i) the clearly documented health consequences of excess sodium consumption; ii) significant direct and indirect costs associated with excess sodium-related health outcomes; and iii) evidence showing that population-level intervention is superior to clinical intervention in terms of cost-effectiveness, returning up to $\$ 11.10$ for every dollar spent and generating tens of billions in direct health-care savings, there is a very strong case for investing in populationlevel sodium reduction interventions that will work. Based on the information contained in the paragraphs above, it is difficult to see how a voluntary approach to product reformulation could achieve a meaningful and equitable reduction, in the absence of any change to the disincentives currently in place. The primary disincentive is financial: reducing sodium by companies means risking profits. However, sodium-related savings to companies translate into significant health care and other costs to society, and if these costs were transferred back to companies, the financial point of resistance would almost certainly disappear. It seems reasonable to conclude that effective population-level sodium reduction will require either a regulatory approach to food product reformulation, or an approach that otherwise effectively removes all disincentives - particularly financial disincentives - to companies to comply.

\footnotetext{
${ }^{141}$ Ricciuto et al. 2008 op. cit.

${ }^{142}$ Op. cit.
} 


\section{REFERENCES}

Aleksandrova K, Pischon T, Weikert C. "Letter: Urinary sodium excretion and cardiovascular disease mortality," JAMA 2011; 306:1083.

Andersen L, Rasmussen LB, Larsen EH, Jakobsen J. "Intake of household salt in a Danish population," Eur J Clin Nutr 2009; 63:598-604.

Bibbins-Domingo K, Chertow GM, Coxson PG, Moran A, Lightwood JM, Pletcher MJ, Goldman L. "Projected effect of dietary salt reductions on future cardiovascular disease," New Engl J Med 2010; 362:590-599.

CBC radio. "Salt: interview with Dr. Norm Campbell, Professor of Medicine at the University of Calgary," The Homestretch (Alberta programming), July 11, 2011. Available online at: http://www.cbc.ca/video/\#/Radio/Local_Shows/Alberta/The_Homestretch/1366093611/ID=2052384638

CIHR Institute of Population and Public Health. Available online at: http://cihr-irsc.gc.ca/e/13777.html

Cecchini M, Sassi F, Lauer JA, Lee YY, Guajardo-Barron V, Chisholm D. "Tackling of unhealthy diets, physical inactivity, and obesity: health effects and cost-effectiveness," Lancet 2010 11/20; 376(9754):1775-1784.

Cobiac LJ, Vos T, Veerman JL. "Cost-effectiveness of interventions to reduce dietary salt intake," Heart 2010; 96:1920-1925.

Dall TM, Fulgoni VL, Zhang Y, Reimers KJ, Packard PT, Astwood JD. "Potential health benefits and medical cost savings from calorie, sodium, and saturated fat reductions in the American diet," Am J Health Promotion 2009; 23:412-422.

Dolega-Cieszkowski JH, Bobyn JP, Whiting SJ. "Dietary intakes of Canadians in the 1990s using population-weighted data derived from the provincial nutrition surveys," Appl Physiol Nutr Metab 2006; 31:753-758

Drewnowski A. “Obesity, diets, and social inequalities," Nutr Rev 2009; 67(Suppl 1):S36-39.

Dubois L, Girard M. "Social position and nutrition: a gradient relationship in Canada and the USA," Eur J Clin Nutr 2001; 55:366-373.

Dutton DJ, Campbell NRC, Elliott C, McLaren L. "A ban on marketing of foods/beverages to children: the who, what, why, and how of a population health intervention," Can J Public Health in press.

Éditeur officiel du Québec. Consumer Protection Act. 1978:248-249.

Elliott C. "Assessing 'fun foods': nutritional content and analysis of supermarket foods targeted at children," Obes Rev 2008; 9:368-377.

Elliott P, Brown I. "Sodium intakes around the world." Background document prepared for the Forum and Technical meeting on Reducing Salt Intake in Populations (Paris 5th-7th October 2006). Geneva: World Health Organization, 2007.

Ezzati M, Lopez AD, Rodgers A, Vander Hoorn S, Murray CJ. "Comparative risk assessment collaborating group," Lancet 2002; 360(9343):1347-60.

Fischer PWF, Vigneault M, Huang R, Arvaniti K, Roach P. "Sodium food sources in the Canadian Diet," Appl Physiol Nutr Metab 2009; 34:884-892. 
Forte JG, Pereira Miguel JM, Pereira Miguel MJ, de Padua F, Rose G. "Salt and blood pressure: a community trial," J Hum Hypertens 1989; 3:179-184.

Garriguet D. "Sodium consumption at all ages," Health Rep 2007; 18:47-52.

Garriguet D. "Canadians' eating habits," Health Rep 2007; 18(2), May.

Gase LN, Kuo T, Dunet DO, Simon PA. "Facilitators of and barriers to implementing a local policy to reduce sodium consumption in the County of Los Angeles government, California, 2009," Prev Chron Dis 2011; 8(2). [Gase et al. 2011a]

Gase LN, Kuo T, Dunet D, Schmidt SM, Simon PA, Fielding JE. "Estimating the potential health impact and costs of implementing a local policy for food procurement to reduce the consumption of sodium in the County of Los Angeles," Am J Public Health 2011; doi:10.2105/AJPH.2011.300138 [Gase et al. 2011b].

Gaziano TA, Bitton A, Anand S, Weinstein MC, International Society of Hypertension. "The global cost of nonoptimal blood pressure," J Hypertens 2009; 27:1472-1477.

Gifford-Jones W. "Can't see the salt for the trees: consumers' taste buds go against a company's best intentions," Toronto Star, July 23, 2011.

Girgis S, Neal B, Prescott J, Prendergast J, Dumbrell S, Turner C, Woodward M. "A one-quarter reduction in the salt content of bread can be made without detection," Eur J Clin Nutr 2003; 57:616-620.

Harris J, Pomeranz J, Lobstein T, Brownell KD. "A Crisis in the Marketplace: How Food Marketing Contributes to Childhood Obesity and What Can Be Done," Anпи Rev Publ Health 2009; 30:211-25.

Hastings G, McDermott L, Angus K, Stead M, Thomson S. The Extent, Nature and Effects of Food Promotion to Children: A Review of the Evidence. World Health Organization 2007. Available online: http://www.who.int/dietphysicalactivity/publications/Hastings_paper_marketing.pdf

He FJ, MacGregor GA. "Importance of salt in determining blood pressure in children: meta-analysis of controlled trials," Hypertens 2006; 48:861-869.

He FJ, MacGregor GA. "A comprehensive review on salt and health and current experience of worldwide salt reduction programmes," J Hum Hypertens 2009; 23:363-384.

Institute of Medicine. Dietary Reference Intakes for Water, Potassium, Sodium, Chloride, and Sulfate. Washington (DC): National Academies Press; 2005.

Jeffrey B. Technical brief of Bill Jeffrey, LLB, National Coordinator, Centre for Science in the Public Interest, before the Hearing on Healthy Living of the House of Commons Standing Committee on Health, February 3, 2011, Ottawa. Available online at:

http://cspinet.org/canada/pdf/english.technicalbrief.pdf

Jeffery B. "The Supreme Court of Canada's Appraisal of the 1980 Ban on Advertising to Children in Quebec: Implications for "Misleading" Advertising Elsewhere," Loyola of Los Angeles Law Review 2006; 39(237).

Joffres MR, Campbell NRC, Manns B, Tu K. "Estimate of the benefits of a population-based reduction in dietary sodium additives on hypertension and its related health care costs in Canada," Can J Cardiol $2007 ; 23: 437-443$.

Laatikainen T, Pietinen P, Valsta L, Sundvall J, Reinivuo H, Tuomilehto J. "Sodium in the Finnish diet: 20 year trends in urinary sodium excretion among the adult population," Eur J Clin Nutr 2006; 60:965-70. 
Lopez AD, Mathers CD, Ezzati M, Jamison DT, Murray CJL. "Global and regional burden of disease and risk factors, 2001: systematic analysis of population health data," Lancet 2006; 367(9524):17471757.

MacGregor GA, Sever PS. "Salt - overwhelming evidence but still no action: can a consensus be reached with the food industry?" BMJ 1996; 312:1287-1289.

Mattes RD, Donnelly D. "Relative contributions of dietary sodium sources," J Am Coll Nutr 1991; 10:383-393

McLaren L, McIntyre L, Kirkpatrick S. "Rose's population strategy of prevention need not increase social inequalities in health," Int J Epidemiol 2010; 39:372-377.

Mohan S, Campbell NRC. "Salt and high blood pressure," Clin Sci 2009; 117:1-11.

Mohan S, Campbell NRC, Willis K. "Effective population-wide public health interventions to promote sodium reduction," CMAJ 2009; 181:605-609.

Nitzke S, Freeland-Graves J, American Dietetic Association. "Position of the American Dietetic Association: total diet approach to communicating food and nutrition information," J Am Diet Assoc 2007; 107:1224-1232.

Penney S. Dropping the Salt: practical steps countries are taking to prevent chronic non-communicable diseases through population-wide dietary salt reduction. Prepared for the Public Health Agency of Canada, 2009.

Penney S. Dropping the Salt 2: A database of global activities and plans to prevent chronic noncommunicable diseases through population-wide dietary salt reduction. Prepared for the Public Health Agency of Canada, 2011.

Pietinen P, Mannisto S, Valsta LM, Sarlio-Lahteenkorva S.” Nutrition policy in Finland," Public Health Nutr 2010; 13:901-906.

Power EM. "Determinants of healthy eating among low-income Canadians, " Can J Public Health 2005; 96(Suppl 3):S37-42.

Puska P. "The North Karelia Project: from community intervention to national activity in lowering cholesterol levels and CHD risk," Eur Heart J 1999; 1(Suppl):S9-13.

Ransome K. "Assessment of dietary intake in accordance with recommendations to reduce the risk of cancer among adult Alberta residents," M.Sc. thesis, Department of Agricultural, Food, and Nutritional Science, University of Alberta, 2001.

Raulio S, Roos E, Prattala R. "School and workplace meals promote healthy food habits," Public Health Nutr 2010; 13:987-992.

Ricciuto L, Lin K, Tarasuk V. "A comparison of the fat composition and prices of margarines between 2002 and 2006, when new Canadian labeling regulations came into effect," Public Health Nutr 2008; 12:1270-1275.

Riciutto LE, Tarasuk V. "An examination of income-related disparities in the nutritional quality of food selections among Canadian households from 1986-2001,” Soc Sci Med 2007; 64:186-198.

Rose G. The strategy of preventive medicine. Oxford: Oxford University Press, 1992. [Reprinted. Rose's strategy of preventive medicine. Oxford: Oxford University Press, 2008.]

Schmidt S. "Feds refused proposed plan to cut sodium," Calgary Herald, December 12, 2011. 
Smith-Spangler CM, Juusola JL, Enns EA, Owens DK, Garber AM. "Population strategies to decrease sodium intake and the burden of cardiovascular disease: a cost-effectiveness analysis," Ann Intern Med 2010; 152:481-487.

Sodium Working Group (SWG). Sodium reduction strategy for Canada - recommendations of the Sodium Working Group, 2010. Report available online at: http://www.hc-sc.gc.ca/fnan/nutrition/sodium/strateg/index-eng.php

Stolarz-Skrzypek K, Kuznetsova T, Lutgarde T, Tikhonoff V, Seidlerova J, Richart T. et al. "Fatal and nonfatal outcomes, incidence of hypertension, and blood pressure changes in relation to urinary sodium excretion," JAMA 2011; 305:1777-1785.

Strazzullo P, D'Elia L, Kandala N-B, Cappuccio FP. "Salt intake, stroke, and cardiovascular disease: meta-analysis of prospective studies," BMJ 2009; 339:b4567.

Tanase CM, Griffin P, Koski KG. "Sodium and potassium in composite food samples from the Canadian Total Diet Study," J Food Composition Analysis 2011; 24:237-243.

Tarasuk V, Fitzpatrick S, Ward H. "Nutrition inequities in Canada," Appl Physiol Nutr Metab 2010; 35:172-179.

Taylor RS, Ashton KE, Moxham T, Hooper L, Ebrahim S. "Reduced dietary salt for the prevention of cardiovascular disease: a meta-analysis of randomized controlled trials (Cochrane review)," Am J Hypertens 2011; 24:843-853.

Truscott A. "Checking up on Health Check," CMAJ 2008; 178:386-387.

Vasan RS, Beiser A, Seshadri S, Larson MG, Kannel WB, D’Agostino RB, Levy D. "Residual lifetime risk for developing hypertension in middle-aged women and men: The Framingham Heart Study," JAMA 2002; 287:1003-1010.

Vatanparast H, Dolega-Cieszkowski JH, Whiting SJ. "Many adult Canadians are not meeting current calcium recommendations from food and supplement intake," Appl Physiol Nutr Metab 2009; 34:191196.

Wang G, Labarthe D. "The cost-effectiveness of interventions designed to reduce sodium intake," $J$ Hypertens 2011; 29:1693-1699.

Webster JL, Dunford EK, Hawkes C, Neal BC. "Salt reduction initiatives around the world," $J$ Hypertens 2011; 29:1043-1050.

Weeks C. "Campbell's adding salt back to its soups," The Globe and Mail, July 14, 2011.

Wilson K. "The complexities of multi-level governance in public health," Can J Public Health 2004; 95:409-412.

World Health Organization (WHO). Diet, nutrition and the prevention of chronic diseases: report of a joint WHO/FAO expert consultation. Geneva: WHO; 2003.

World Health Organization (WHO 2007) Reducing salt intake in populations: Report of a WHO forum and technical meeting, Paris 2006. p 3. www.who.int/dietphysicalactivity/Salt_Report_VC_april07.pdf.

World Health Organization (WHO 2008). Salt as a vehicle for fortification. Report of a WHO Expert Consultation, Luxembourg, 21-22 March 2007.

http://whqlibdoc.who.int/publications/2008/9789241596787_eng.pdf.

World Health Organization (WHO 2010a). Creating an enabling environment for population-based salt reduction strategies: report of a joint technical meeting held by WHO and the Food Standards Agency, United Kingdom, July 2010. Geneva: WHO Press, 2010. 
World Health Organization (WHO 2010b). Sodium: Surveillance, Monitoring, and Evaluation. Strategies to monitor and evaluate population sodium consumption and sources of dietary sodium, and relevant knowledge, attitudes and behaviours. Proceedings of a technical meeting jointly convened by WHO and the Government of Canada. Calgary, October 2010.

This work was funded by The School of Public Policy, University of Calgary.

\section{About the Author:}

Lindsay McLaren is an Associate Professor and Alberta Innovates - Health Solutions Population Health Investigator in the Department of Community Health Sciences and the Institute for Public Health at the University of Calgary. 


\section{ABOUT THIS PUBLICATION}

The School of Public Policy Research Papers provide in-depth, evidence-based assessments and recommendations on a range of public policy issues. Research Papers are put through a stringent peer review process prior to being made available to academics, policy makers, the media and the public at large. Views expressed in The School of Public Policy Research Papers are the opinions of the author(s) and do not necessarily represent the view of The School of Public Policy.

\section{OUR MANDATE}

The University of Calgary is home to scholars in 16 faculties (offering more than 80 academic programs) and 36 Research Institutes and Centres including The School of Public Policy. Under the direction of Jack Mintz, Palmer Chair in Public Policy, and supported by more than 100 academics and researchers, the work of The School of Public Policy and its students contributes to a more meaningful and informed public debate on fiscal, social, energy, environmental and international issues to improve Canada's and Alberta's economic and social performance.

The School of Public Policy achieves its objectives through fostering ongoing partnerships with federal, provincial, state and municipal governments, industry associations, NGOs, and leading academic institutions internationally. Foreign Investment Advisory Committee of the World Bank, International Monetary Fund, Finance Canada, Department of Foreign Affairs and International Trade Canada, and Government of Alberta, are just some of the partners already engaged with the School's activities.

For those in government, The School of Public Policy helps to build capacity and assists in the training of public servants through degree and non-degree programs that are critical for an effective public service in Canada. For those outside of the public sector, its programs enhance the effectiveness of public policy, providing a better understanding of the objectives and limitations faced by governments in the application of legislation.

\section{DISTRIBUTION}

Our publications are available online at www.policyschool.ca.

\section{DISCLAIMER}

The opinions expressed in these publications are the authors' alone and therefore do not necessarily reflect the opinions of the supporters, staff, or boards of The School of Public Policy.

\section{COPYRIGHT}

Copyright (C) 2012 by The School of Public Policy.

All rights reserved. No part of this publication may be reproduced in any manner whatsoever without written permission except in the case of brief passages quoted in critical articles and reviews.

\section{ISSN}

1919-112x SPP Research Papers (Print)

1919-1138 SPP Research Papers (Online)

\section{DATE OF ISSUE}

June 2012

\section{MEDIA INQUIRIES AND INFORMATION}

For media inquiries, please contact Morten Paulsen at 403-453-0062.

Our web site, www.policyschool.ca, contains more information about The School's events, publications, and staff.

\section{DEVELOPMENT}

For information about contributing to The School of Public Policy, please contact Courtney Murphy by telephone at 403-210-7201 or by e-mail at cmurphy@ucalgary.ca.

\section{EDITOR}

Timothy Giannuzzi 


\title{
RECENT PUBLICATIONS BY THE SCHOOL OF PUBLIC POLICY
}

\author{
A WHITE PAPER* ON REFORMING CANADA'S TRANSPORTATION POLICIES FOR THE 21ST CENTURY \\ http:/ / policyschool.ucalgary.ca/?q=content/ white-paper-reforming-canadas-transportation-policies-21s- \\ century.pdf \\ Brian Flemming | June 2012
}

PREVENTING DOMESTIC VIOLENCE IN ALBERTA: A COST SAVINGS PERSPECIVE

http:/ / policyschool.ucalgary.ca/ ?q=content/ preventing-domestic-violence-alberta-cost-savings-

perspective.pdf

Lana Wells, Casey Boodt and Herb Emery | June 2012

\section{NEGOTIATED SETTLEMENTS: LONG-TERM PROFITS AND COSTS}

http:// policyschool.ucalgary.ca/?q=content/ negotiated-settlements-long-term-profits-and-costs.pdf G Kent Fellows | May 2012

\section{REFORMING THE TAX MIX IN CANADA}

http:// policyschool.ucalgary.ca/?q=content/reforming-tax-mix-canada.pdf

Bev Dahlby | April 2012

TAXING CONSUMPTION OR INCOME: DU PAREIL AU MÊME?

http:/ / policyschool.ucalgary.ca/sites/default/ files/research/cnossen-taxing-consumption.pdf Sijbren Cnossen | April 2012

THE GST/HST: CREATING AN INTEGRATED SALES TAX IN A FEDERAL COUNTRY

http:// policyschool.ucalgary.ca/ sites/default/files/research/bird-gst-hst.pdf Richard M. Bird | April 2012

A PROPOSAL TO CREATE A PAN-CANADIAN ENERGY INFORMATION ORGANIZATION (CEIO) http:/ / policyschool.ucalgary.ca/ sites/default/files/research/m-moore-pancanadian.pdf Michal C. Moore | April 2012

ASSISTED REPRODUCTION POLICY IN FEDERAL STATES: WHAT CANADA SHOULD LEARN FROM AUSTRALIA http:/ / policyschool.ucalgary.ca/ sites/default/files/research/ dave-snow-art-final.pdf Dave Snow and Rainer Knopff | April 2012

THE ROLE OF CROWN CORPORATIONS IN THE CANADIAN ECONOMY - AN ANALYTICAL FRAMEWORK http:// policyschool.ucalgary.ca/sites/default/files/research/ privatization-crown-corp.pdf Edward M. Iacobucci and Michael J. Trebilcock | March 2012

TANTALUS UNBOUND: GOVERNMENT POLICY AND INNOVATION IN CANADA

http:// policyschool.ucalgary.ca/sites/default/files/research/macintosh-final.pdf Jeffrey G. MacIntosh | March 2012

IMPLICATIONS OF THE RECOMMENDATIONS OF THE EXPERT PANEL ON FEDERAL SUPPORT TO RESEARCH AND DEVELOPMENT

http:/ / policyschool.ucalgary.ca/ sites/default/files/research/mintzmanning-fed-supp-1.pdf

Preston Manning and Jack Mintz | March 2012

SMART ENVIRONMENTAL POLICY WITH FULL-COST PRICING

http:/ / policyschool.ucalgary.ca/sites/default/files/research/olewiler-online.pdf

Nancy Olewiler | March 2012 